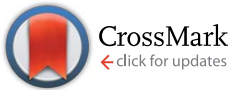

Cite this: RSC Adv., 2015, 5, 95191

Received 29th September 2015 Accepted 15th October 2015

DOI: $10.1039 / c 5 r a 19849 f$

www.rsc.org/advances

\section{Zn(II) complex with 2-quinolinecarboxaldehyde selenosemicarbazone: synthesis, structure, interaction studies with DNA/HSA, molecular docking and caspase- 8 and -9 independent apoptose induction $\uparrow$}

\author{
Nenad R. Filipović, ${ }^{a}$ Snežana Bjelogrlić, ${ }^{\mathrm{b}}$ Aleksandar Marinković, ${ }^{\mathrm{c}}$ Tatjana Ž. Verbić, \\ Ilija N. Cvijetić, ${ }^{e}$ Milan Senćanski, ${ }^{f}$ Marko Rodić, ${ }^{9}$ Miroslava Vujčić, ${ }^{\mathrm{h}}$ Dušan Sladić, ${ }^{d}$ \\ Zlatko Striković, ${ }^{d}$ Tamara R. Todorović ${ }^{\star d}$ and Christian D. Muller ${ }^{\star i j}$
}

\begin{abstract}
A new Zn(II)-based potential chemotherapeutic agent was synthesized from the ligand 2quinolinecarboxaldehyde selenosemicarbazone (Hqasesc). Single crystal X-ray diffraction analysis showed that the $\mathrm{Zn}(॥)$ complex consists of a cation $\left[\mathrm{Zn}(\text { Hqasesc })_{2}\right]^{2+}$, two perchlorate anions and one ethanol solvent molecule. The interaction of calf thymus (CT) DNA and human serum albumin (HSA) with the $\mathrm{Zn}(I)$ complex was explored using absorption and emission spectral methods, and also has been supported by molecular docking studies. The complex has more affinity to minor DNA groove than major, with no significant intercalation. The HSA interaction studies of the complex revealed the quenching of the intrinsic fluorescence of the HSA through a static quenching mechanism. The antitumor activity of the ligand and the complex against pancreatic adenocarcinoma cell line (AsPC-1) and acute monocytic leukemia (THP-1) cells was evaluated. Both compounds are strong concentrationdependent apoptosis inducers in THP-1 cells. While Hqasesc in AsPC-1 cells induces apoptosis only at the highest concentration, treatment with the $\mathrm{Zn}$ complex shows a concentration-dependent apoptotic response, where the treated cells are arrested in the G1-to-S phase accompanied with extensive activation of caspase- 8 and -9 . These results indicate that the ligand and $\mathrm{Zn}(I)$ complex display cell phenotype specific activity.
\end{abstract}

\section{Introduction}

Thiosemicarbazones are condensation products of thiosemicarbazide and carbonyl compounds, which have been extensively studied as NS bidentate ligands in coordination chemistry. They possess imine nitrogen and sulfur donor atoms from the thiosemicarbazide moiety., ${ }^{\mathbf{1 , 2}}$ The coordination capacity of this class of ligands may be extended if there is a donor atom(s) from the carbonyl compound in a position(s) suitable to form a chelate ring(s). This class of compounds is well known to possess a wide range of pharmacological properties. ${ }^{3}$ Studies from the 1960s indicated that the mechanism of action of thiosemicarbazones involves the inhibition of DNA synthesis. ${ }^{4}$ When it was proven that tumor cells lose their ability
${ }^{a}$ Faculty of Agriculture, University of Belgrade, Nemanjina 6, Belgrade, Serbia

${ }^{b}$ National Cancer Research Center of Serbia, Pasterova 14, Belgrade, Serbia

${ }^{c}$ Faculty of Technology and Metallurgy, University of Belgrade, Karnegijeva 4, Belgrade, Serbia

${ }^{d}$ Faculty of Chemistry, University of Belgrade, Studentski trg 12-16, Belgrade, Serbia. E-mail: tamarat@chem.bg.ac.rs

'Innovation Center of the Faculty of Chemistry, University of Belgrade, Studentski trg 12-16, Belgrade, Serbia

${ }^{f}$ Center for Multidisciplinary Research, Institute of Nuclear Sciences "Vinča", University of Belgrade, Belgrade, Serbia

${ }^{g}$ Department of Chemistry, Faculty of Sciences, University of Novi Sad, Trg Dositeja Obradovića 4, Novi Sad, Serbia

${ }^{h}$ Institute of Chemistry, Technology and Metallurgy, University of Belgrade, Njegoševa 12, Belgrade, Serbia
iLaboratoire d'Innovation Thérapeutique, UMR 7200, Faculté de Pharmacie, Université de Strasbourg, 67401 Illkirch, France.E-mail: cdmuller@unistra.fr

${ }^{j}$ Plateforme eBioCyt, Faculté de Pharmacie \& Féderation Translationnelle de Médecine, Université de Strasbourg, 67401 Illkirch, France

$\dagger$ Electronic supplementary information (ESI) available: FT-IR (Fig. S1) and NMR (Fig. S2-S9) spectra; cyclic voltammograms (Fig. S10); pH dependent UV-Vis spectra (Fig. S11 and S12); packing diagrams (Fig. S13 and S14); sigmoidal dose-response curves (Fig. S15); Stern-Volmer plot (Fig. S16); modified Stern-Volmer plot (Fig. S17); the plot of $\ln K_{\mathrm{a}}$ vs. 1/T (Fig. S18); double-log plot (Fig. S19); fluorescence spectral overlap (Fig. S20); conformations of the complex in the DNA duplex (Fig. S21); the location of the HSA-Zn complex binding site (Fig. S22); numbering of atoms (Scheme S1); hydrogen bonding geometry (Table S1); interactions of HSA binding site (Table S2). CCDC 1413656 and 1413657. For ESI and crystallographic data in CIF or other electronic format see DOI: 10.1039/c5ra19849f 
to convert ribonucleotides to deoxyribonucleotides after treatment with $\mathrm{N}$-heteroaromatic thiosemicarbazone obtained from 2-formylpyridine, ribonucleotide reductase (RR) was marked as the main target for NNS chelating thiosemicarbazones. Chelation of iron from the RR active site was proposed to be the reason for enzyme inactivation. ${ }^{4}$ Recent findings indicate other mechanisms of thiosemicarbazone action: reactive oxygen species (ROS) generation, DNA binding, topoisomerase II inhibition, mitochondria disruption, inhibition of protein synthesis and multidrug resistance protein inhibition..$^{4-6}$

Despite the fact that various thiosemicarbazones have been developed and even patented as pharmaceuticals, ${ }^{7}$ the synthesis and biological activity investigation of this type of compounds is still a topic of interest. Some recent studies resulted in new thiosemicarbazone molecules, which are more active than standard chemotherapeutics. ${ }^{8-13}$ One strategy for the improvement of biological activity of thiosemicarbazones is the synthesis of their metal complexes. Coordination of thiosemicarbazones to metals enhances their lipophilicity by orienting the lipophilic and aromatic parts outwards from the complex molecules toward the solvent. ${ }^{6}$ Metal complexes may be a vehicle for the activation of thiosemicarbazones by increasing their ability to diffuse through the semipermeable membrane of cells, and complexes often show less side effects and different bioactivities in comparison to metal-free ligands. ${ }^{3}$

Selenosemicarbazones are selenium analogues of thiosemicarbazones and their biological activity has been studied in a lesser extent, probably because selenium was considered as a toxic element for humans up to the late $1950 \mathrm{~s} .{ }^{14}$ Another reason might be the instability of this type of compounds as is apparent from the precipitation of elemental selenium during the complexation of selenosemicarbazones, modification of ligands with the evolution of hydrogen selenide, or oxidation with the formation of diselenide bridges. ${ }^{14}$ However, some of synthesized selenosemicarbazones and their complexes showed good biological activity. ${ }^{15-18} \mathrm{~A}$ few comparative studies indicated that selenosemicarbazones showed similar or even better biological activities than the corresponding thiosemicarbazones and their complexes. ${ }^{19-24}$ We previously synthesized and characterized $\mathrm{Zn}$ (II) complexes with N-heteroaromatic selenosemicarbazones of 2,6-diacetylpyridine, 2-formylpyridine and quinoline-2-carboxaldehyde $\left(\mathrm{H}_{2}\right.$ dapsesc, Hfpsesec and Hqasesc, respectively). ${ }^{25-27}$ In the corresponding complexes the ligands were coordinated via $\mathrm{N}_{\text {aromatic }}, \mathrm{N}_{\mathrm{imin}}$, and Se atoms. The $\mathrm{Zn}$ complexes with pyridine derivatives were the subject of antitumor investigations, ${ }^{27-31}$ while the complex with a quinoline derivative was unsuitable due to low solubility. The complex with $\mathrm{H}_{2}$ dapsesc showed a strong dose-dependent cytotoxic activity, with an $\mathrm{IC}_{50}$ value in the range 13-60 $\mu \mathrm{M}$ on six human carcinoma cell lines, as determined by a colorimetric assay after $24 \mathrm{~h}$ incubation. ${ }^{30}$ On human breast cancer (MDA361) and human colon cancer (LS174) cell lines, the $\mathrm{IC}_{50}$ values for this complex were of the same order of magnitude as $\mathrm{IC}_{50}$ values of cisplatin (CDDP). The $\mathrm{Zn}$ complex with a formylpyridine derivative showed a strong cytotoxic effect on the five treated human cancer cell lines, in the range of the activity of CDDP, as determined by a colorimetric assay after 48 and 72 $\mathrm{h}$ of incubation. ${ }^{27}$ It is worth mentioning that this complex had a low toxicity on normal endothelial cells (EA.hy926), lower in comparison to the activity on treated cancer cell lines, and even lower than the activity of CDDP on EA.hy926 cells.

In order to continue our investigation on the antitumor activity of selenosemicarbazone complexes with biometals we have synthesized a new Zn complex with the Hqasesc ligand and evaluated ligand and complex activities on a different cancer cell model than used in our previous studies. While organizing current research, our guiding idea was to test whether these compounds can display full-scale anticancer activity. Extensive research of cancer biology and behavior has revealed that the same cells, which mediate tumor growth, are also responsible for resistance to treatment and tumor relapse, and these have been referred as Cancer Stem Cells (CSCs). ${ }^{32}$ An important feature of CSCs is their extensive genomic heterogeneity, which results in persistent cancer sub-clones with a unique genomic and epigenomic profile, and each of these sub-clones is probably endowed with a different drug-resistant phenotype. Furthermore, it was shown that another characteristic of CSCs is the reversible transition between epithelial and mesenchymal states in carcinoma. The epithelial-mesenchymal transition (EMT) is a physiological process that occurs during embryonic development, which is defined by biochemical changes in epithelial cells that lead to the acquisition of mesenchymal properties, including loss of cell adhesion and increased migratory capacity. ${ }^{33}$ In cancer, the EMT generates cells with apparent CSC features and has been associated with more aggressive tumors. ${ }^{34}$ Therefore, evidence from experimental models and clinical studies strongly indicate that the major goal of the current drug development should be to create an efficient strategic drug with ability to induce apoptotic death in all tumor cells including CSCs, as a way to achieve a cancer cure. For that reason, in the present work we have explored the activity of the Hqasesc ligand and its $\mathrm{Zn}$ complex against pancreatic adenocarcinoma cell line (AsPC-1), which possesses characteristics of epithelial-mesenchymal transition (EMT)type cells, bearing resistance to three conventional chemotherapeutic agents (gemcitabine, 5-fluorouracil, and CDDP). ${ }^{35,36}$ Antitumor activity of the compounds was also evaluated on nonCSC acute monocytic leukemia (THP-1) cells. Owing to the noted characteristics, the chosen cell lines represent excellent in vitro models for the investigation of the Hqasesc ligand and its Zn complex against the heterogeneity and plasticity of cancer cells.

\section{Results and discussion}

The $\mathrm{Zn}(\mathrm{II})$-complex with the ligand Hqasesc was prepared by a template reaction starting from zinc(II) perchlorate hexahydrate, 2-quinolinecarboxaldehyde and selenosemicarbazide (mole ratio $1: 2: 2$, respectively). The complex is soluble in $\mathrm{MeOH}, \mathrm{EtOH}, \mathrm{MeCN}, \mathrm{DMF}$ and DMSO at room temperature. Molar conductivity measurements showed that the complex is a $1: 2$ electrolyte. Based on these results, as well as results of elemental analysis, spectroscopic and X-ray diffraction study 
(vide infra), the formula of the complex can be written as $\left[\mathrm{Zn}(\text { Hqasesc })_{2}\right]\left(\mathrm{ClO}_{4}\right)_{2} \cdot \mathrm{EtOH}(\mathbf{1})$.

\section{IR and NMR spectroscopy}

The experimental IR spectrum of $\mathbf{1}$ (Fig. S1a, ESI $\dagger$ ) was interpreted in terms of a calculated one (Fig. S1b, ESI†े) at the B97D/ TZVP level of theory (see Experimental section for details) and with comparison to the spectrum of the metal-free ligand. In the IR spectrum of Hqasesc there are sharp medium intensity bands in the region $3340-3080 \mathrm{~cm}^{-1}$ which are assigned to the $\nu\left(\mathrm{NH}_{2}\right)$ and $\nu(\mathrm{NH})$ stretching vibrations. ${ }^{26}$ The lack of a large systematic shift of these bands in the IR spectrum of 1 indicates that there is no interaction between the terminal nitrogen atom and zinc ion. As had been previously observed in other selenosemicarbazone complexes, ${ }^{25-28}$ in the IR spectrum of $\mathbf{1}$ there is a systematic shift of the $\nu(\mathrm{C}=\mathrm{N})$ band to a higher frequency in comparison to that in the corresponding ligand $\left(1607 \mathrm{~cm}^{-1}\right.$ in Hqasesc; $1617 \mathrm{~cm}^{-1}$ in 1). Also, in the spectrum of 1 a sharp and strong band at $\sim 1100 \mathrm{~cm}^{-1}$ originating from the perchlorate ion can be observed.

1D $\left({ }^{1} \mathrm{H}\right.$ and $\left.{ }^{13} \mathrm{C}\right)$ and 2D (COSY, NOESY, ${ }^{1} \mathrm{H}^{-13} \mathrm{C}$ HSQC and ${ }^{1} \mathrm{H}^{-13} \mathrm{C}$ HMBC) spectra of $\mathbf{1}$ were recorded in DMSO- $d_{6}$ and are shown in Fig. S2-S7 (ESI $\dagger$ ) together with the atom numbering scheme (Scheme S1, ESI $\dagger$ ). NMR spectral data for Hqasesc are in full agreement with previously published data. ${ }^{26}$ In all the 1D spectra of 1 there is only one set of signals, indicating the presence of just one form of the complex in solution. Based on the presence of the $\mathrm{H}-\mathrm{N} 3$ signal at $12.56 \mathrm{ppm}$ in the ${ }^{1} \mathrm{H}$ NMR spectrum of $\mathbf{1}$, the ligand is coordinated to $\mathrm{Zn}$ (II) in the neutral form. It has already been documented that NMR signal shifts for $\mathrm{Zn}$-thio(seleno)semicarbazone complexes in comparison to corresponding signals for free ligands are less pronounced than for other chalcogensemicarbazone d-metal complexes. ${ }^{25,27,37,38}$ Coordination of the $\mathrm{Zn}$ (II) ion to Hqasesc gives rise to downfield shifts of all protons in the ${ }^{1} \mathrm{H}$ NMR spectrum (Fig. S8a, ESI $†$ ), together with shifts of almost all signals in the ${ }^{13} \mathrm{C}$ NMR spectrum (Fig. S8b, ESI $\dagger$ ). The quinoline nitrogen atom coordination is corroborated by a significant downfield shift of the signal of $\mathrm{C} 4-\mathrm{H}$ in the proton NMR and the signal of $\mathrm{C} 4$ in the carbon NMR spectrum, as well as the upfield shift of signals of C8a and $\mathrm{C} 2$ in the carbon NMR spectrum of $\mathbf{1}$. The downfield shift of the C9 signal in the ${ }^{13} \mathrm{C}$ NMR spectrum indicates imine nitrogen coordination, while due to selenium atom coordination the signals of $\mathrm{N} 4 \mathrm{Ha}$ and $\mathrm{N} 4 \mathrm{Hb}$ are significantly shifted downfield. A shift of the signal of the selenone carbon atom $(\mathrm{C}=\mathrm{Se})$ in the spectrum of $\mathbf{1}$ is similar to those reported for analogous $\mathrm{Zn}$ chalcogensemicarbazone complexes. ${ }^{25,27,37}$ The complex 1 was quite stable, as can be seen from the proton spectra of a freshly prepared sample and a sample after 24 h (Fig. S9, ESI $\dagger$ ).

\section{Cyclic voltammetry}

The redox behavior of Hqasesc and $\mathbf{1}$ have been investigated by cyclic voltammetry (Fig. S10, ESI $\dagger$ ) in a potential range from +1.2 to $-2.0 \mathrm{~V}$ relative to a $\mathrm{Ag} / \mathrm{AgCl}$ reference electrode. Repeated scans, as well as different scan rates, showed that dissociation of the ligand does not take place in $\mathbf{1}$. In the cyclic voltammogram of the ligand, two cathodic peaks at -1.38 and $-1.93 \mathrm{~V} v$ s. $\mathrm{Ag} / \mathrm{AgCl}$ were observed. The first peak can be attributed to imine bond reduction since a similar value $(-1.33$ V) was assigned to a pyridinium analogue of Hqasesc. ${ }^{39}$ It is reasonable to assume that the second peak resulted from selenoamide reduction. Namely, similar values for benzil bis(thiosemicarbazone) $(-1.440$ and $-1.746 \mathrm{~V}$ vs. $\mathrm{Ag} / \mathrm{AgCl})$ were assigned to imine and thioamide reduction, respectively. ${ }^{40} \mathrm{In}$ the reverse scan process, no anodic peaks were observed, indicating that these electrochemical processes were coupled with a chemical reaction (EC mechanism). ${ }^{41}$ In the cyclic voltammogram of 1 the corresponding cathodic peaks are shifted to positive positions $(-1.35$ and $-1.84 \mathrm{~V} v s$. $\mathrm{Ag} / \mathrm{AgCl})$ due to the metal-ligand orbital interactions, as was noticed for the $\mathrm{Zn}$ complex with 4-phenyl-1-[(4-methoxyphenyl)methylene]-thiosemicarbazide. ${ }^{42}$ In the range from 0 to $-1.3 \mathrm{~V}$ additional reduction peaks are observed in the cyclic voltammogram of $\mathbf{1}$, as in the case of the $\mathrm{Zn}$-benzil bis(thiosemicarbazone) complex. ${ }^{40}$ The number of reduction peaks is equal for Hqasesc and $\mathbf{1}$ which indicates that the complex is stable - the $\mathrm{Zn}$ (II) ion is "hidden" for reduction in the chelate structure. On the other hand, the number of oxidation peaks in the cyclic voltammograms of Hqasesc and $\mathbf{1}$ is different (Hqasesc: 0.32 and $-0.02 \mathrm{~V}$ vs. $\mathrm{Ag} / \mathrm{AgCl} ; 1: 0.30,-0.04$ and $-0.52 \mathrm{~V} v$ s. $\mathrm{Ag} / \mathrm{AgCl})$. The additional oxidation peak can be assigned to $\mathrm{Zn}$ (II) ion oxidation, which is proven by addition of $\mathrm{Zn}\left(\mathrm{ClO}_{4}\right)_{2} \cdot 6 \mathrm{H}_{2} \mathrm{O}$ to a solution of $\mathbf{1}$ (Fig. S10, ESI†).

\section{Determination of acidity constants of Hqasesc}

The acidity constants of the ligand were determined using spectrophotometric titration at $T=298 \pm 1 \mathrm{~K}$. Within the studied $\mathrm{pH}$ range (1.65-11.91) Hqasesc acts as a sparingly soluble ampholyte (Scheme 1).

UV-Vis spectra of Hqasesc in $\mathrm{pH}$ ranges $1.65-5.17$ and 5.1711.91 are shown in Fig. S11a and S12a (ESI $\dagger$ ). The existence of two $\mathrm{pH}$ regions with clearly visible isosbestic points indicates that the two $\mathrm{p} K_{\mathrm{a}}$ values are well separated $\left(\Delta \mathrm{p} K_{\mathrm{a}}>3\right)$. The existence of isosbestic points proves that the only process in solution within both $\mathrm{pH}$ ranges is the proteolytic equilibrium shown in scheme 1. This makes the spectrophotometric method valid for $\mathrm{p} K_{\mathrm{a}}$ value determination. Acidity constant $\left(K_{\mathrm{a} 1}\right.$ and $K_{\mathrm{a} 2}$ ) values were calculated according to transformed forms of the classical spectrophotometric equation, ${ }^{43}$ which gives a linear dependence (for details see Experimental part). A value of $K_{\mathrm{a} 1}$ was obtained as the slope from the corresponding linear dependencies at four wavelengths $(287,327,341,390 \mathrm{~nm})$, while

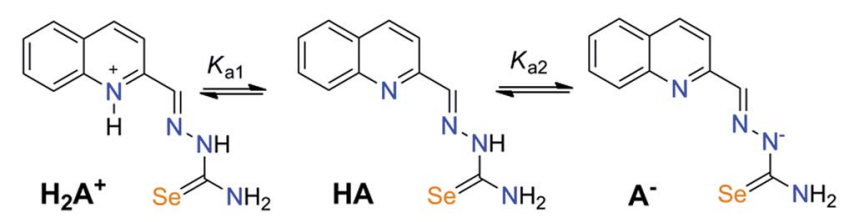

Scheme 1 Proteolytic equilibria of Hqasesc in aqueous media. HA, as neutral form of Hqasesc, is represented in one tautomeric form, while all tautomers coexist in solution. 
$K_{\mathrm{a} 2}$ was obtained as the slope from the corresponding linear dependencies at three wavelengths (266, 330, 365 nm). Examples are shown in Fig. S11b and S12b (ESI $\dagger$ ). The obtained $\mathrm{p} K_{\mathrm{a} 1}$ and $\mathrm{p} K_{\mathrm{a} 2}$ values are given in Table 1 and the corresponding distribution diagram in Fig. 1. It should be noted that all determined constants represent macro ionization constants. As shown in Scheme $1, K_{\mathrm{a} 1}$ represents the dissociation of the protonated quinoline nitrogen, while $K_{\mathrm{a} 2}$ accounts for different contributions of the selenone tautomer (shown in Scheme 1) and selenenol tautomer (not shown).

\section{Description of the solid-state structures}

A summary of data collection and refinement parameters for Hqasesc and $\mathbf{1}$ is given in Table 2. The molecular structure of Hqasesc is presented in Fig. 2, and selected bond lengths and bond angles are presented in Table 3.

Validation of the Hqasesc structure with MERCURY CSD ${ }^{44}$ shows no significant deviation from the common values found in the Cambridge Structural Database. ${ }^{45}$ Thus, the structural parameters of Hqasesc are quite usual for this arrangement of $\mathrm{sp}^{2}$ hybridized atoms. It is evident that electron delocalization is pronounced throughout the whole ligand molecule, and only the C2-N2 distance corresponds to a localized double bond. It is interesting to note that the ligand is comprised of two nearly planar parts - the quinoline aldehyde moiety and the selenosemicarbazide moiety - which are mutually inclined at $20.38(10)^{\circ}$. Moreover, the molecule adopts a conformation in which the quinoline $\mathrm{N} 1$ and azomethine $\mathrm{N} 2$, as well as the azomethine $\mathrm{N} 2$ and Se1 atoms are mutually in trans positions. This implies that conformational rearrangement is necessary for metal binding in the expected and observed tridentate way. Molecular arrangement in the crystal structure of the ligand is governed by a network of hydrogen bonds formed between N4 and N1 and N3 and Se1 (Fig. S13 and Table S1, ESI $\dagger$ ) so that molecules are grouped into sheets parallel to the $(-101)$ crystallographic plane.

The asymmetric part of the unit cell in the crystal structure of $\mathbf{1}$ is comprised of the complex cation $\left[\mathrm{Zn}(\text { Hqasesc) })_{2}\right]^{2+}$ (Fig. 3), two perchlorate anions and one ethanol molecule. Important structural parameters are collected in Table 3. The complex cation has approximately C2 symmetry (pseudo-symmetry axis is the bisector of N1-Zn1-N1A angle) and is comprised of two meridionally placed ligand molecules chelating the $\mathrm{Zn}$ (II) atom. Hqasesc molecules are coordinated in their neutral forms as tridentate NNSe donors, through the quinoline and azomethine

Table 1 Acidity constant values of Hqasesc $\left(\mathrm{p} K_{\mathrm{a} 1}\right.$ and $\left.\mathrm{p} K_{\mathrm{a} 2}\right)$, given as mean $\mathrm{p} K_{\mathrm{a}}$ value \pm confidence interval $(\mathrm{Cl})$ at $95 \%$ probability

\begin{tabular}{llll}
\hline Wavelength $(\mathrm{nm})$ & $\mathrm{p} K_{\mathrm{a} 1}$ & $\begin{array}{l}\text { Wavelength } \\
(\mathrm{nm})\end{array}$ & $\mathrm{p} K_{\mathrm{a} 2}$ \\
\hline 287 & 3.52 & 266 & 7.16 \\
327 & 3.43 & 330 & 7.18 \\
341 & 3.40 & 365 & 7.08 \\
390 & 3.42 & & \\
Average \pm CI & $3.44 \pm 0.08$ & & $7.14 \pm 0.13$
\end{tabular}

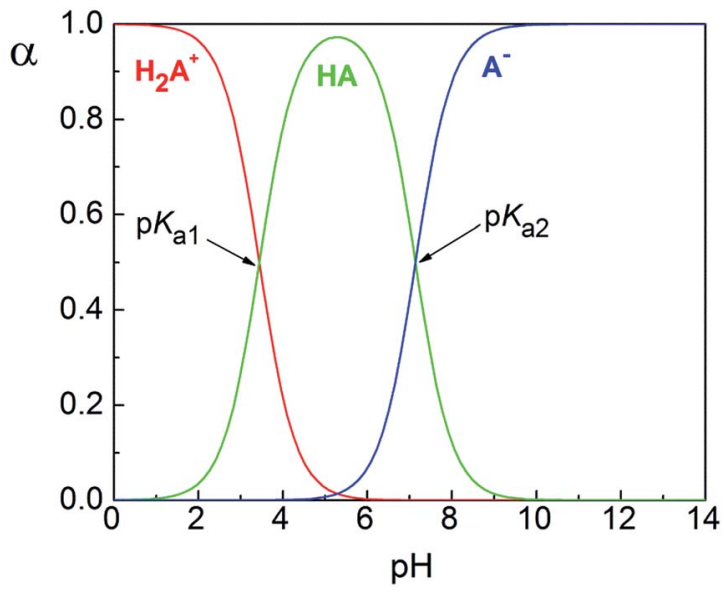

Fig. 1 Hqasesc distribution diagram. Species notation as in Scheme 1.

nitrogen atoms, and selenium atom. This coordination mode of the ligand is already observed in $\mathrm{Ni}$ (II) and $\mathrm{Co}$ (III) complexes of the formula $\left[\mathrm{Ni}(\text { qasesc })_{2}\right] \cdot \mathrm{DMSO}^{26}$ and $\left[\mathrm{Co}(\text { qasesc })_{2}\right]$ $\mathrm{BF}_{4} \cdot 2 \mathrm{H}_{2} \mathrm{O},{ }^{46}$ and as expected, it is analogous to NNS coordination of structurally related thiosemicarbazones. ${ }^{4-49}$ In that way, each ligand forms two five-membered metallocycles and all show a high degree of planarity. The exception is five-membered metallocycle Se1-Zn1-N2-N3-C1, which is significantly puckered, and may be described as twisted on the Zn1-N2 bond. The coordination octahedron is distorted, as a consequence of constraints implied by the ligand's bite angles which are in the range $73.74(7)-79.44(5)^{\circ}$.

Metal-ligand bonds fall in a wide range (2.1808(18)2.6233(3) $\AA$ ), which is in line with the different covalent radii of nitrogen and selenium donor atoms. Quinoline nitrogen atoms form slightly longer bonds than azomethine nitrogen atoms, which is also observed in $\mathrm{Ni}$ (II) and $\mathrm{Co}(\mathrm{III})$ complexes with Hqasesc. $^{26,46}$ On the other hand, significantly longer bonds are formed between Se and $\mathrm{Zn}$ atoms, as expected. It is worth mentioning that $\mathrm{Zn}$-Se bonds are not equivalent, and that the Se1 atom forms an almost $0.1 \AA$ longer bond [2.6233(3) $\AA$ ] compared to Se1A [2.5592(3) A] . Moreover, the Se1 atom is part of the only significantly puckered metallocycle. Ligand deformation occurs in a way that the distance between Se1 and Se1A is maximized ( $\mathrm{Se} 1 \cdots \mathrm{Se} 1 \mathrm{~A}=3.8831(3) \AA$ ). This can be visualized by torsion angles $\tau(\mathrm{C} 2-\mathrm{N} 2-\mathrm{N} 3-\mathrm{C} 1)=-169.7(2)^{\circ}$, and $\tau(\mathrm{N} 2-\mathrm{N} 3-$ $\mathrm{C} 1-\mathrm{Se} 1)=-6.9(3)^{\circ}$. Similar behavior is observed in [Ni(qasesc) $\left.)_{2}\right]$, where the Se $\cdots$ Se distance is 3.7955(5) Å however, in that complex, both ligands are equally deformed, whereas in $\left[\mathrm{Zn}(\text { Hqasesc })_{2}\right]^{2+}$ only one ligand is deformed. A proposed plausible explanation is that the that bis-ligand structure of the cation places two selenium atoms closer than the sum of their van der Waals (vdW) radii $\left(r_{\mathrm{Se}}=1.9 \AA\right.$ ) , and distortion is the consequence of steric repulsion. ${ }^{26}$ Nevertheless, in [Co(qasesc $)_{2}$ ] $\mathrm{BF}_{4} \cdot 2 \mathrm{H}_{2} \mathrm{O}$ and $\mathrm{Fe}(\mathrm{III})$ complex $\left[\mathrm{Fe}(\mathrm{L})_{2}\right]\left[\mathrm{FeCl}_{4}\right] \cdot 1 / 3 \mathrm{MeCN}(\mathrm{HL}=3-$ azabicyclo[3.2.2]nonane-3-carboselenoic acid, [1-(2-pyridinyl) ethylidene]hydrazide $)^{50}$ the Se*Se distances $[3.349(1)$ and 3.494(3) A, respectively] are significantly less than the sum of their $\mathrm{vdW}$ radii. The comparison of $\mathbf{M}-\mathrm{Se}$ bond lengths and $\mathrm{Se} \cdots \mathrm{Se}$ 
Table 2 Pertinent crystallographic and refinement data for Hqasesc and 1

\begin{tabular}{|c|c|c|}
\hline & Hqasesc & 1 \\
\hline Molecular formula & $\mathrm{C}_{11} \mathrm{H}_{10} \mathrm{~N}_{4} \mathrm{Se}$ & $\mathrm{C}_{24} \mathrm{H}_{26} \mathrm{Cl}_{2} \mathrm{~N}_{8} \mathrm{O}_{9} \mathrm{Se}_{2} \mathrm{Zn}$ \\
\hline Formula weight & 277.19 & 864.72 \\
\hline Habitat & Irregular & Block \\
\hline Color & Orange & Red \\
\hline Crystal size $\left(\mathrm{mm}^{3}\right)$ & $0.47 \times 0.37 \times 0.21$ & $0.70 \times 0.54 \times 0.30$ \\
\hline$a(\AA)$ & $8.19022(13)$ & $11.14856(17)$ \\
\hline$b(\AA)$ & $11.07458(14)$ & $13.88140(18)$ \\
\hline$c(\AA)$ & $12.09766(18)$ & $20.8541(3)$ \\
\hline$\beta\left(0^{\circ}\right)$ & $92.6837(13)$ & $98.5190(15)$ \\
\hline$V\left(\AA^{3}\right)$ & $1096.09(3)$ & $3191.73(8)$ \\
\hline$Z$ & 4 & 4 \\
\hline Independent reflections, $R_{\text {int }}$ & $2714,0.023$ & $10890,0.021$ \\
\hline Reflections with $I>2 \sigma(I)$ & 2368 & 8743 \\
\hline Parameters, restraints & 157,0 & 435,9 \\
\hline Goodness-of-fit on $F^{2}$ & 1.206 & 1.072 \\
\hline$R, \mathrm{w} R(I>2 \sigma(I))$ & $0.025,0.034$ & $0.037,0.052$ \\
\hline$R, \mathrm{w} R$ (all data) & $0.075,0.104$ & $0.102,0.109$ \\
\hline$\Delta \rho \max$ and $\min \left(\mathrm{e} \AA^{-3}\right)$ & $0.47,-0.31$ & $0.84,-0.59$ \\
\hline
\end{tabular}

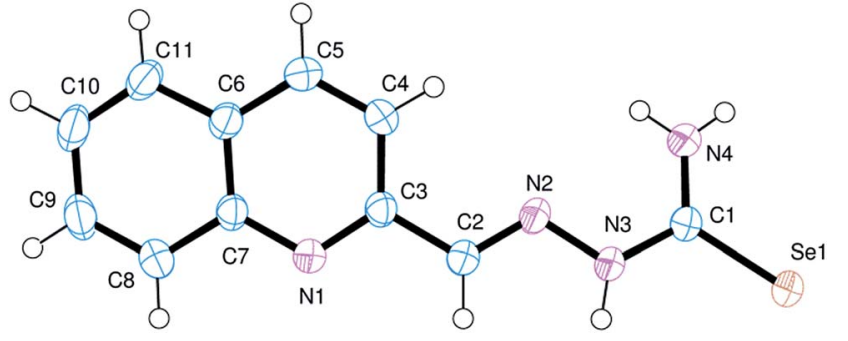

Fig. 2 ORTEP drawing of molecular structure of Hqasesc at 50\% probability level.

distances above mentioned shows that these properties are approximately in direct proportion. Since Se ${ }^{\cdots}$ Se distances in $\mathrm{Co}$ (III) and Fe(III) complexes are shorter than the sum of the vdW radii, it appears that in these cases the strength of the coordination bonds compensate the steric repulsion, whereas in $\mathrm{Ni}(\mathrm{II})$ and $\mathrm{Zn}$ (II) complexes the longer metal-ligand bonds allow deformation of the coordination polyhedron to minimize steric repulsion between non-bonded adjacent Se atoms.

Intra-ligand bond lengths in the structure of $\mathbf{1}$ are quite similar to those found in the free ligand. A CSD search for C-Se single and double bond length distribution in Se-coordinated compounds having a $\mathrm{N}-\mathrm{C}(-\mathrm{Se})-\mathrm{N}$ fragment, reveals very broad and overlapped ranges: $1.81-1.93 \AA$ (67 hits, mean $=1.87(2) \AA)$ for formal double bonds, and 1.81-1.97 $\AA$ (58 hits, mean = 1.88(3) ̊) for formal single bonds. In this context, Se1-C1 and Se1A-C1A bond lengths in the complex (1.842(3) and 1.842(2) $\AA$, respectively) are slightly shorter than the average $\mathrm{C}=$ Se double bond in compounds with structurally related fragments.
Table 3 Selected bond lengths $(\AA)$ and bond angles $\left({ }^{\circ}\right)$ of Hqasesc and 1

\begin{tabular}{lll}
\hline & Hqasesc & 1 \\
\hline Zn1-Se1 & - & $2.6233(3)$ \\
Zn1-Se1A & - & $2.5592(3)$ \\
Zn1-N1 & - & $2.2211(17)$ \\
Zn1-N1A & - & $2.2177(17)$ \\
Zn1-N2 & - & $2.1971(18)$ \\
Zn1-N2A & - & $2.1808(18)$ \\
C2-N2 & $1.278(3)$ & $1.275(3)$ \\
C2A-N2A & - & $1.271(3)$ \\
N2-N3 & $1.364(3)$ & $1.355(3)$ \\
N2A-N3A & - & $1.362(3)$ \\
C1-N3 & $1.348(3)$ & $1.339(3)$ \\
C1A-N3A & - & $1.340(3)$ \\
C1-Se1 & $1.841(2)$ & $1.842(3)$ \\
C1A-Se1A & - & $1.842(2)$ \\
N1-Zn1-N2 & - & $73.74(7)$ \\
N1A-Zn1-N2A & - & $74.02(7)$ \\
N2-Zn1-Se1 & - & $77.84(5)$ \\
N2A-Zn1-Se1A & - & $79.44(5)$ \\
N1-Zn1-Se1 & - & $149.70(5)$ \\
N1A-Zn1-Se1A & - & $152.98(5)$ \\
\end{tabular}

Overall the crystal structure is comprised of interleaved cation sheets and anion + solvent sheets, progressing parallel to the ac plane (Fig. S14, ESI $\dagger$ ). In addition to the electrostatic attraction, cations and perchlorate anions are connected with numerous hydrogen bonds. The two selenosemicarbazone moieties of a cation are differently involved in these interactions as hydrogen bond donors. Namely, $\mathrm{N}(4) \mathrm{H}_{2}$ and $\mathrm{N}(3) \mathrm{H}$ groups 


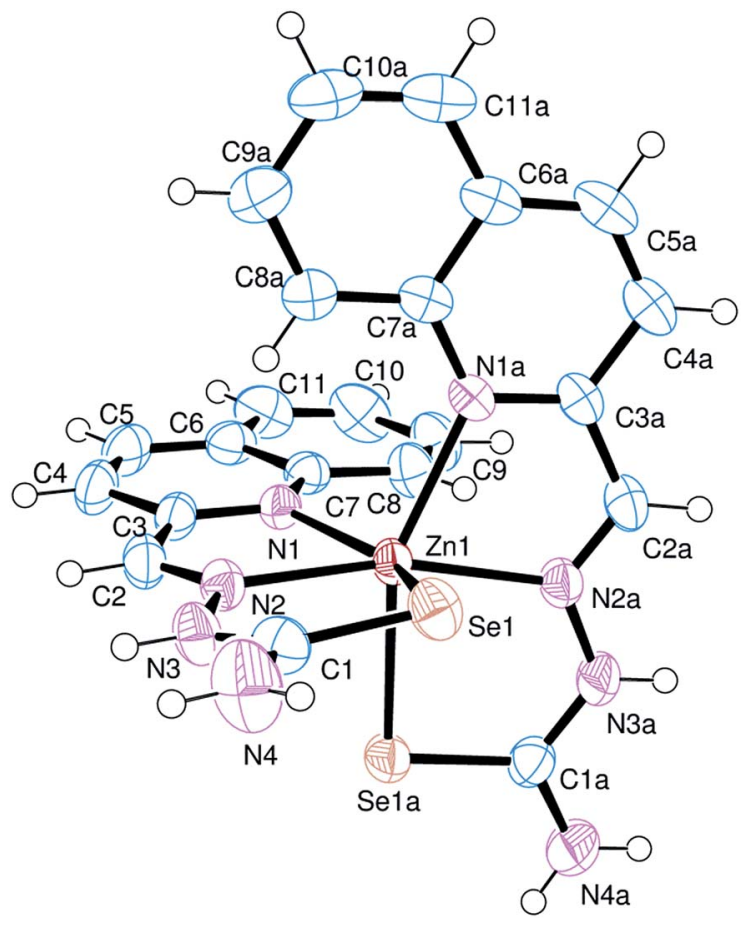

Fig. 3 The ORTEP diagram of complex cation $\left[\mathrm{Zn}(\text { Hqasesc })_{2}\right]^{2+}$ in 1 drawn at 50\% probability level.

are bonded exclusively to perchlorate oxygen atoms, whereas $\mathrm{N}(4 \mathrm{~A}) \mathrm{H}_{2}$ and $\mathrm{N}(3 \mathrm{~A}) \mathrm{H}$ groups are bonded to ethanol oxygen, while the $\mathrm{N}(4 \mathrm{~A}) \mathrm{H}_{2}$ group is additionally bonded to another perchlorate anion. The only significant cation-cation interaction within the sheet is the weak N4A-H4D $\cdots \mathrm{Se}^{i i i}($ iiii: $-x, y,-1 /$ 2) hydrogen bond (Table S1, ESI $\dagger$ ). The hydroxyl group of the ethanol molecule exhibits positional disorder, and in both sites (O9A and O9B) it acts as a N(3A)H hydrogen bond acceptor, but acts as a hydrogen bond donor to perchlorate anions in opposite directions.

\section{Free radical-scavenging activity}

Because selenium antioxidants can prevent oxidative damage, numerous animal and clinical trials have investigated the ability of these compounds to prevent the oxidative stress that is an underlying cause of cancer. Interest in selone $(\mathrm{C}=\mathrm{Se})$ antioxidants can be attributed to naturally occurring selenoneine, a compound which effectively scavenges the 1,1-diphenyl-2picrylhydrazyl (DPPH) radical. ${ }^{51}$ In our previous study the free radical-scavenging activity of selenosemicarbazones and their metal complexes by the ABTS [2,2'-azino-bis(3-ethylbenzothiazoline-6-sulphonic acid)] method were determined. ${ }^{14}$ Our results showed that Hqasesc and its isomeric analogue H8qasesc (8-quinolinecarboxaldehyde selenosemicarbazone) had an excellent ABTS cation radical-scavenging effect, which was greater than that of reference antioxidant vitamin C. Coordination to $\mathrm{Pt}(\mathrm{II}), \mathrm{Pd}(\mathrm{II}), \mathrm{Cd}(\mathrm{II}), \mathrm{Co}(\mathrm{III})$ and $\mathrm{Ni}$ (II) reduced the antioxidant activity in the corresponding complexes. However, some selenosemicarbazone complexes still showed better activity than vitamin C. ${ }^{14}$
The proton donating ability of Hqasesc and $\mathbf{1}$ was assayed using a protocol for the determination of radical scavenging activity, the DPPH method..$^{52} \mathrm{IC}_{50}$ values were calculated from the plotted graph of scavenging activity against the concentrations of the samples. $\mathrm{IC}_{50}$ is defined as the total antioxidant necessary to decrease the initial DPPH radical by $50 \%$. $\mathrm{IC}_{50}$ was calculated for all compounds based on the percentage of DPPH radicals scavenged. Ascorbic acid was used as the reference compound (positive control) with concentrations from 50 to 500 $\mu \mathrm{g} \mathrm{mL}^{-1}$. These results corroborate our previous finding obtained by the ABTS method that Hqasesc has excellent free radical-scavenging activity, better than vitamin C. Coordination to $\mathrm{Zn}$ reduces the activity of the corresponding complex $\mathbf{1}$, but still $\mathbf{1}$ is two times more active than vitamin $\mathrm{C}$.

\section{Evaluation of pro-apoptotic activity}

An initial experiment was organized to test the ability of Hqasesc and 1 to induce cell death in treated malignant populations. Both compounds were applied in a range of six concentrations and left for $24 \mathrm{~h}$ on THP-1 and AsPC-1 cells. Afterwards, cells were evaluated for the occurrence of cell death in terms of quality and quantity. There are several modalities of cell death that are classified according to morphological characteristics and measurable biochemical features. ${ }^{53}$ In the current study Annexin-V/propidium iodide (PI) staining was used, i.e. a quantitative method that provides objective assessment of cell viability alongside an accurate incidence of apoptotic and necrotic cells in the analyzed sample. This method is based on detection of phosphatidylserine (PS) externalization in the plasma membrane surface of apoptotic cells. This is the earliest event in this programmed cell death arisen as one of the "eat-me" signals that contributes to the recognition and removal of apoptotic bodies by phagocytosis. ${ }^{54}$ The PS is also a binding site for Annexin-V, while PI serves as a cell membrane non-permeant dye excluded from viable cells. Such double assay staining allows differentiation between viable cells and those in apoptosis: early (Annexin- $\mathrm{V}$ positive cells), late stages (Annexin- $V$ and PI positive cells) and necrosis (PI only stained cells).

As represented in Fig. 4, both compounds on THP-1 cells induced a concentration-dependent increase in percentage of apoptotic cells, while appearance of necrosis was at the level of untreated control. In cells treated with Hqasesc, apoptosis was detected starting from a concentration of $30 \mu \mathrm{M}$, which also was the concentration that induced the highest percent of doublestained cells. An increase of Hqasesc concentration on treated cells was followed by rise of early apoptotic events and sequential reduction of cells in late apoptosis, whereas percentages of vital cells remained almost the same in samples treated within the range 30-75 $\mu \mathrm{M}$. Treatment with 1 induced massive apoptosis already at a concentration of $10 \mu \mathrm{M}$. It is interesting that at this concentration almost all apoptotic cells were in the late stages whereas the incidence of pre-apoptotic events was barely above the non-treated control. As the concentration of 1 was increased, the percentage of early apoptotic cells increased at the expense of viable cells while the 


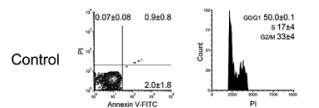

Hqasesc
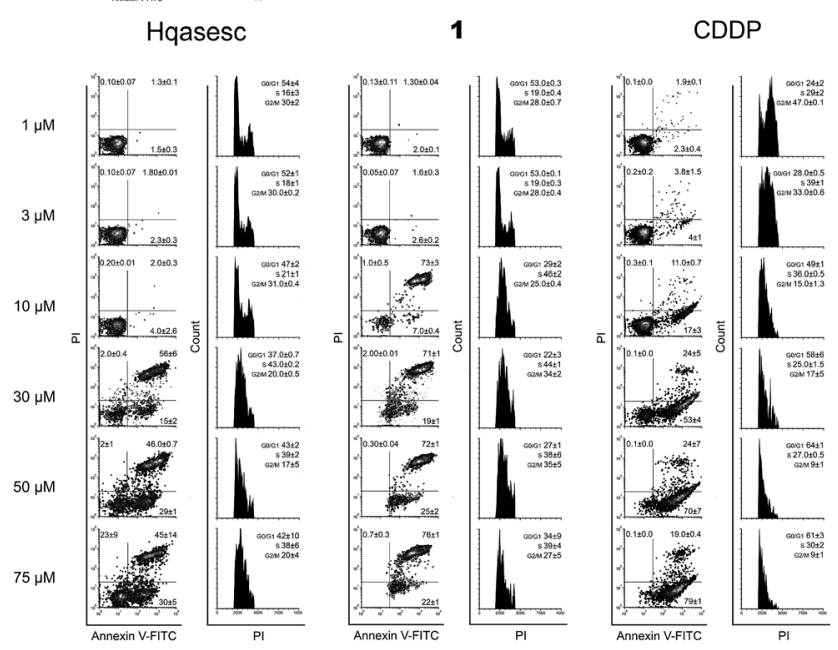

Fig. 4 Activity of Hqasesc, 1 and CDDP on THP-1 cells. Annexin- $V$ and $\mathrm{PI}$ double staining (left panels for apoptosis) and PI single staining (right panels for cell cycle) of THP-1 cells after $24 \mathrm{~h}$ treatment with Hqasesc, 1 and CDDP applied in a range of six dose concentrations. In AnnexinV/PI plots cells are discriminated as viable (non-stained cells, lower left quadrant), cells in early phases of apoptosis (Annexin- $V$ single stained cells, lower right quadrant), cells in late phases of apoptosis (doublestained cells, upper right quadrant), and cells in necrosis (PI single stained cells, upper left quadrant). The same cells evaluated with Annexin-V/PI were fixed in ethanol right after analysis, left overnight and assayed the next day for cell cycle phases of mitotic division with the PI single staining method after RNAse treatment. Frequency of cells found in G0/G1, S and G2/M phases was determined according to non-treated control population. All results are expressed as the mean\% \pm SD of two replicates from independent experiments, while compounds were placed on the same microtiter plate in both experiments with the same non-treated control for Annexin-V/PI and cell cycle analysis.

incidence of double stained cells remained unchanged. Contrary to Hqasesc and 1, treatment of THP-1 cells with CDDP induced only their accumulation at the early phase of apoptosis. Even the escalation of CDDP concentration could not facilitate execution and termination of apoptosis after $24 \mathrm{~h}$ of incubation. It is expected from a successful anticancer agent not only to trigger apoptotic death, but also to conduct the cells through the whole process of programmed cell death. If all the chains of cascaded actions of apoptosis are accomplished within a short period of time, the treated cell will have less chance to develop resistance to the mechanism which initiated the apoptotic response. Therefore, compared to CDDP both Hqasesc and 1 displayed a more favorable mode of activity on the THP-1 cell line.

Likewise, a striking lack of early apoptotic events was also evident in AsPC-1 cells treated with 1 (Fig. 5). In these cells the first double-stained events were read-out in samples treated with 1 at $30 \mu \mathrm{M}$, and their percentage increased dependent on the concentration of 1 . On the other hand, in AsPC-1 cells treated with Hqasesc, apoptosis was found only in the sample treated with the highest applied concentration and was not

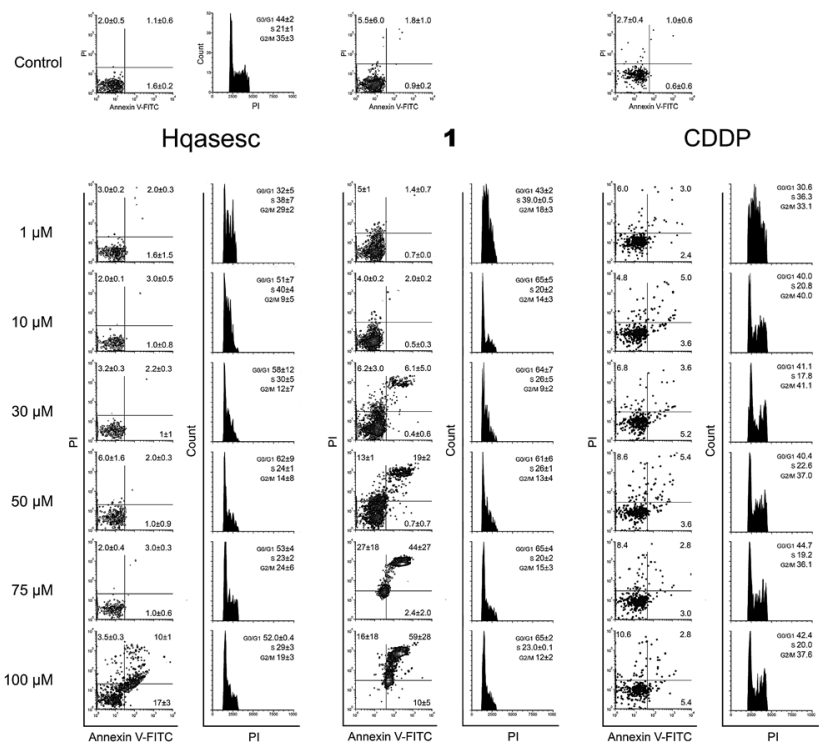

Fig. 5 Activity of Hqasesc, 1 and CDDP on AsPC-1 cells. Annexin-V and PI double staining (left panels for apoptosis) and PI single staining (right panels for cell cycle) of AsPC-1 cells after $24 \mathrm{~h}$ treatment with Hqasesc, 1 and CDDP applied in a range of six dose concentrations. In Annexin-V/PI plots, cells are discriminated as viable (non-stained cells, lower left quadrant), cells in early phases of apoptosis (Annexin-V single stained cells, lower right quadrant), cells in late phases of apoptosis (double-stained cells, upper right quadrant), and cells in necrosis (PI single stained cells, upper left quadrant). The same cells evaluated with Annexin-V/PI were fixed in ethanol right after analysis, left overnight and assayed the next day for distribution within phases of mitotic division with the PI single staining method in the presence of RNAse. The frequency of cells found in G0/G1, S and G2/M phases was determined according to the non-treated control population. All results for Hqasesc and 1 are expressed as the mean\% \pm SD of two replicates from independent experiments. Results for CDDP are expressed as the \% of gated cells from one replicate considering the additional experiment was not performed due to inactivity of CDDP on AsPC-1 cells. Investigated compounds were placed on different plates, with separate non-treated control cells for Annexin-V/PI reading, while the control for cell cycle analysis represents the mean $\% \pm$ SD of five replicates.

accompanied by an increased percentage of necrotic cells. These results left it unclear whether THP-1 and AsPC-1 cells, labeled with both Annexin-V and PI, after treatment with 1 were actually apoptotic or necrotic since it was shown that doublestained cells can be interpreted as both. ${ }^{55}$ In order to make a clear discrimination between apoptosis and necrosis as the endpoint event of the treatments, we decided to manipulate these two possible scenarios by using shorter incubation periods with a single appointed concentration of each compound. This concentration was chosen to be the $\mathrm{ED}_{50}$ computed according to the percentage of Annexin- $\mathrm{V}$ labeled cells irrespective of the PI positive cells. As seen from doseresponse curves (Fig. S15, ESI $\dagger$ ), both Hqasesc and 1 showed significantly stronger activities against THP-1 cells, with several times higher $\mathrm{ED}_{50}$ concentrations on the AsPC-1 cell line. The $\mathrm{ED}_{50}$ concentration for CDDP on THP-1 cells was comparable to the value for Hqasesc, but three times higher compared to 1. On 
the AsPC-1 cell line CDDP did not induce either a significant percentage of cell death, or $\mathrm{ED}_{50}$ changes.

\section{Impact on apoptotic responses of co-incubation with the pancaspase inhibitor Z-VAD-fmk}

Apoptosis is a process of biochemical events that lead to characteristic morphological changes of the cell and finally its death. These biochemical events are predetermined and include cascaded activations of different effectors, starting from a triggering incidence up to mitochondrial outer membrane permeabilization, which is marked as the "point of no return" of the lethal process. ${ }^{53}$ The central role in regulation of apoptosis belongs to caspases, a family of cysteine proteases. If caspases play an essential role in THP-1- and AsPC-1-treated cells, then the pancaspase inhibitor $N$-benzyloxycarbonyl-Val-Ala-Asp $(\mathrm{O}-$ Me) fluoromethyl ketone (Z-VAD-fmk) should inhibit the treatment-dependent response. We performed a $6 \mathrm{~h} \mathrm{co-}$ incubation of Z-VAD-fmk with either Hqasesc or $\mathbf{1}$ applied at their $\mathrm{ED}_{50}$ concentrations on THP-1 and AsPC-1 cells, respectively, while the effect of Z-VAD-fmk on apoptosis induced by CDDP was investigated only on the THP- 1 cell line. After incubation, the cells were stained with Annexin-V/PI, and the percentages of cell death inhibition were computed taking all Annexin-V positive events into account (Fig. 6A).

According to the percent of inhibited apoptotic response for Z-VAD-fmk co-treated cells, all investigated compounds induced apoptosis by both, caspase-dependent and caspaseindependent pathways. In THP-1 cells, average reduction of apoptotic death varied from 20 to $35 \%$ with no significant difference between treatments. On the contrary, the addition of Z-VAD-fmk to Hqasesc and 1 treatment on AsPC-1 cells had higher impact on cell survival as compared to THP-1 cells. These results indicated that Hqasesc and $\mathbf{1}$ induce apoptosis in THP-1 and AsPC-1 cell line by different pathways. Also, the high percent of apoptosis reduction by Z-VAD-fmk in AsPC- 1 cell line treated with 1 clearly indicates that double-stained events found after $24 \mathrm{~h}$ of incubation were cells in advanced phases of apoptosis rather than necrosis.

\section{Assessment of caspase activity}

Results with Z-VAD-fmk imposed the need to assess which pathway is activated in regulation of apoptotic death by treatment of the cells with Hqasesc and 1. Caspases that regulate apoptosis can be divided into two major groups: caspase initiators (caspases 2, 8, 9, and 10), and caspase effectors (caspases 3,6 , and 7). Further, apoptosis can be triggered through different biochemical routes, which in general are divided into "intrinsic" and "extrinsic" pathways. ${ }^{56,57}$ Briefly, the term "extrinsic apoptotic pathway" indicates that apoptosis is triggered by extracellular death signals that are sensed and propagated by specific transmembrane receptors, a pathway regulated by caspase- 8 or -10 . Initiation of the "intrinsic apoptotic pathway" comes as a result of bioenergetics and metabolic catastrophe triggering caspase- 9 . Therefore, we evaluated caspase-8 and -9 activities after $6 \mathrm{~h}$ of treatment at $\mathrm{ED}_{50}$ concentrations of Hqasesc and $\mathbf{1}$ in both cell lines.
Non-treated THP-1 cells show a constitutive caspase-9 activity, while activated caspase-8 was never recorded. After 6 $\mathrm{h}$ of treatment with Hqasesc, only a modest increase in caspase9 activity was found whereas activity of caspase-8 stayed on the level of non treated cells (Fig. 6B). Incubation of THP-1 cells with 1 and CDDP did not induce increase any activity of these two caspases. Such a result in the case of CDDP might be quite understandable considering it induced only a small percentage of cells in the advanced phase of apoptosis, in correspondence to the percentage of apoptosis inhibited with Z-VAD-fmk cotreatment. However, as already discussed above, treatment of THP-1 cells with 1 induced a massive apoptotic response of low $\mathrm{ED}_{50}$ value with almost $40 \%$ of apoptosis inhibited by Z-VADfmk. All these facts indicate that there is probably another caspase-dependent pathway of apoptosis regulation involving another caspase rather than caspase-8 and -9. For instance caspase-2 should be taken into consideration. A lack of known caspase-2 substrates has been the major obstacle for its categorization within one of the two major apoptotic pathways. Caspase-2 is activated by cellular stress induced by DNA damage, cytoskeletal disruption or radical oxygen species formation, and it acts in functional compensation with caspase$9{ }^{58}$ Thus, further investigation will be required to identify the possible role of caspase-2 in THP-1 cell apoptosis induced by Hqasesc and 1.

Constitutive activity of caspase-9 is also found in AsPC- 1 cells. Again, incubation with Hqasesc resulted in a slight increase of caspase-9 and -8 activities (Fig. 6C). On the contrary, treatment with 1 triggered massive activation of both caspases. Such a result confirms that complex $\mathbf{1}$ is a strong apoptotic inducer for AsPC-1 CSCs. Nevertheless, considerable impact of Z-VAD-fmk on apoptosis induced by Hqasesc indicates a possibility that its activity on AsPC-1 cells might also be related to the activation of caspase-2, rather than caspase-8 and -9.

\section{Cell cycle distribution}

In the current study certain improvements of the standard experimental protocols were applied. In particular, cells treated for $24 \mathrm{~h}$ and stained with Annexin-V/PI for evaluation of proapoptotic activity, after analysis on flow cytometer, were fixed overnight with ethanol and subsequently assessed for cell cycle distribution. This manipulation brought considerable advantages such as the decrease in amount of analyses, and more importantly the reduction of incidental divergences in experimental results since the same treated cells were used to provide two different but complementary read-outs.

As represented in Fig. 4, Hqasesc and 1 stimulated THP-1 cells arrest in the $\mathrm{S}$ phase of mitotic division in a concentration-dependent manner. This phenomenon coincided with the occurrence of apoptosis. In AsPC-1 cells treatment with Hqasesc and $\mathbf{1}$ induced arrest at the S phase only at the lowest concentration of $1 \mu \mathrm{M}$, which, following an increase of applied concentrations, was shifted toward G1-to-S blockage (Fig. 5). Thus, the incidence of apoptosis in AsPC- 1 cells could not be related to a particular alteration in cell distribution within mitotic division. Interestingly, CDDP on THP-1 cells initially 
A

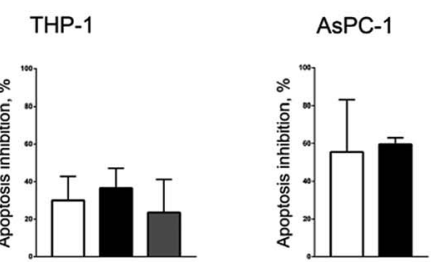

B

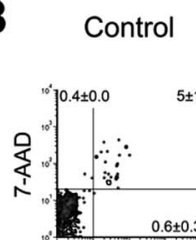

Hqasesc

\section{1}
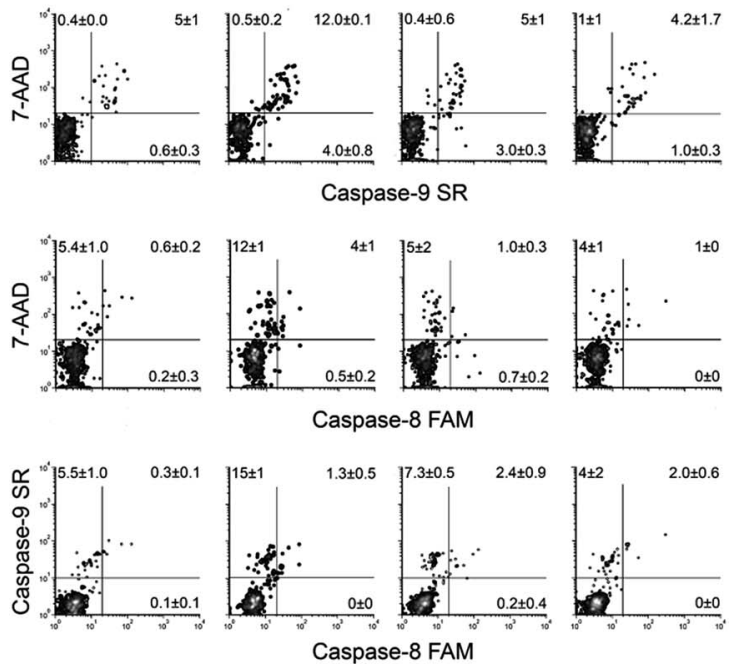

\section{C}

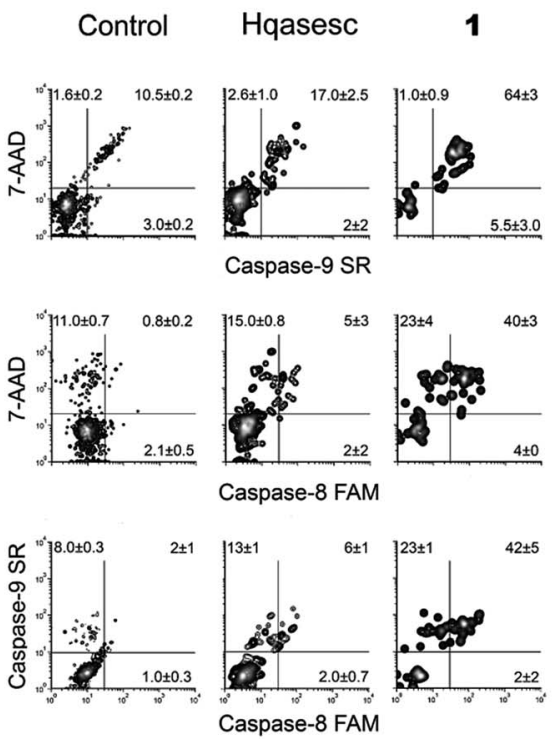

Fig. 6 (A) Percent of apoptosis inhibition induced by $6 \mathrm{~h}$ co-incubation of Hqasesc (white bar), 1 (black bar) and CDDP (gray bar) applied in $E_{50}$ concentrations with pancaspase inhibitor Z-VAD-fmk. Results are expressed as the mean \pm SD of two replicates from independent experiments. The role of caspases in apoptosis induced by Hqasesc, 1 and CDDP. Caspase- 8 and -9 activities determined in cells after $6 \mathrm{~h}$ incubation with Hqasesc, 1 and CDDP on THP-1 cells (B) and Hqasesc and 1 on AsPC-1 cells (C), all applied in ED 50 concentrations. In the plots cells are discriminated as live (not stained with either caspase nor 7-AAD), mid stage apoptotic cells (cells stained with either caspase-8 or -9 , but negative to 7-AAD), late stage apoptotic cells (cells stained with either of caspase- 8 or -9 and with 7-AAD), and necrotic cells (cells not stained with either caspase- 8 nor -9 , but positive for 7-AAD). induced S-to-G2 arrest at the lowest applied concentration, shifting to a blockage in the $\mathrm{S}$ phase at $3 \mu \mathrm{M}$, and finally generated G1-to-S arrest, which matches with apoptotic response (Fig. 4). These results indicate the following: Hqasesc and 1 have different modes of activity on THP-1 compared to CDDP, and Hqasesc and 1 induce apoptosis in THP-1 and AsPC1 cells by dissimilar mechanisms. One might suppose that Hqasesc and 1 in THP-1 cells interfere with DNA replication, while in AsPC-1 cells they initiate activation of G1/S checkpoints which impedes cell transition into the $S$ phase and the beginning of DNA replication. To determine the ability of the more active compound (1) to interact with DNA, the next set of experiments on DNA binding and DNA cleavage were performed.

\section{DNA binding studies}

Non-covalent interactions of transition metal complexes with DNA include intercalation between the bases, binding to minor groove, major groove, sugar-phosphate backbone and three-way junction. ${ }^{59}$ Electronic absorption spectroscopy is an effective method for examining the binding mode. The hypochromic effect induced by the DNA on a spectrum of a bound ligand is one indicator of the binding mode. In general, intercalators have stronger hypochromicities than the corresponding groove binders. The absorption spectra of metal complexes bound to DNA through intercalation exhibit significant hypochromism and red shift due to the strong $\pi \rightarrow \pi^{*}$ stacking interaction between the aromatic chromophore ligand of the metal complex and the base pairs of DNA. ${ }^{60}$ Metal complexes, which bind non-intercalatively or electrostatically with DNA, may result in either hyperchromism or hypochromism. ${ }^{61}$ Groove binding typically results in only subtle changes in the structure, and DNA remains essentially in an unperturbed B form. In contrast, intercalation in which a planar ligand moiety is inserted between adjacent base pairs, results in a substantial change in DNA structure and causes lengthening, stiffening and unwinding of the helix. Zinc-containing compounds are regarded as one of the most promising alternatives to CDDP as anticancer drugs. ${ }^{62}$ It has been reported that zinc complexes can interact with DNA by different modes. ${ }^{63,64}$ In this work, spectroscopic methods were employed to ascertain the interaction mode of 1 with calf thymus (CT) DNA.

Electronic absorption spectra of $\mathbf{1}$ in aqueous buffer media, both in the absence and the presence of CT-DNA, are shown in Fig. 7. The absorption spectrum of 1 (Fig. 7A) exhibits two peaks (at 296 and $343 \mathrm{~nm}$ ) and two shoulders (at 240-250 and 425-450 $\mathrm{nm})$. The interaction of the complex with CT-DNA was monitored by the disappearance of shoulder bands and peak at 296 $\mathrm{nm}$. After interaction with CT-DNA, the absorption band at 343 $\mathrm{nm}$ exhibited hyperchromism of about $-22 \%$ with the lowest concentration of 1 . With the increase of concentration of 1 ( $3 \times$ $10^{-5}$ and $6 \times 10^{-5} \mathrm{M}$ ), hypochromism (the value reaches $26 \%$ and $50 \%$, respectively) followed by blue shift (10 $\mathrm{nm}$ at maximal

Results are expressed as the mean $\% \pm$ SD of two replicates from independent experiments. 
A
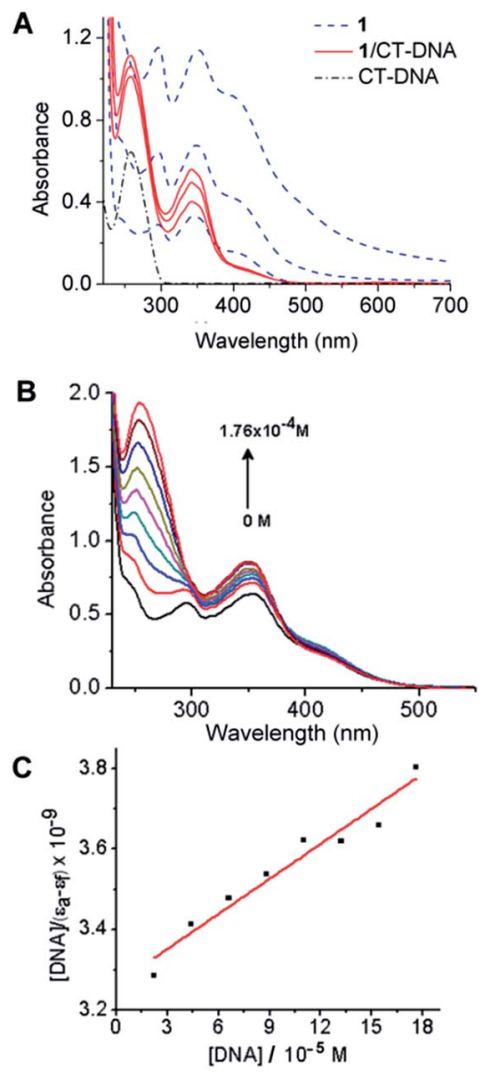

Fig. 7 Determination of binding constant by absorption titration of 1 with CT-DNA. (A) Absorption spectra of CT-DNA $\left(8.81 \times 10^{-7} \mathrm{M},-\cdot-\cdot\right.$. CT-DNA), $1\left(1,3\right.$, and $6 \times 10^{-5} \mathrm{M}$, - complex 1) and CT-DNA in presence 1,3 , and $6 \times 10^{-5} \mathrm{M}$ of the complex (-1/CT-DNA). (B) Absorption spectra of $1\left(3 \times 10^{-5} \mathrm{M}\right)$ without $(\mathrm{O} \mathrm{M})$ and with CT-DNA at different concentrations $(2.202,4.405,6.607,8.81,11.01,13.21,15.41$ and $\left.17.62 \times 10^{-5} \mathrm{M}\right)$; (C) plot of [DNA] $/\left(\varepsilon_{\mathrm{A}}-\varepsilon_{\mathrm{F}}\right)$ versus [DNA].

performed concentration), occurs as the result of possible intercalative interactions between the complex and CT-DNA due to the strong stacking interaction between the aromatic chromophore of 1 and the base pairs of DNA.

In the spectra of $\mathrm{Zn}$ (II)-complex/CT-DNA, a peak at $258 \mathrm{~nm}$ was also observed with an increase in absorption intensity, Fig. 7A (hyperchromism was calculated as $-57 \%,-64 \%$ and $-72 \%$ ). The absorption intensity at $258 \mathrm{~nm}$ was increased due to exposure of purine and pyrimidine bases due to complex binding. In order to obtain information on affinity of $\mathbf{1}$ for CTDNA, a spectroscopic titration of the solution of the complex with an increasing concentration of CT-DNA was performed (Fig. 7B). The absorbance at $258 \mathrm{~nm}$ was monitored for each concentration of DNA. The intrinsic binding constant $K_{\mathrm{B}}$ of the complex (Fig. 7C) was calculated as $8.92 \times 10^{4} \mathrm{M}^{-1}$ (for calculation details see Experimental section). The value of binding constant was lower than reported for a classical intercalator, i.e. a range from $10^{6}$ to $10^{7} \mathrm{M}^{-1}{ }^{65}$ The value of $K_{\mathrm{B}}$ for $\mathbf{1}$ was comparable to those for other metal complexes, ${ }^{64,66}$ suggesting minor groove binding of $\mathbf{1}$. The spectral changes that occur when 1 was added to CT-DNA, as well as the absence of isosbestic points in these spectra, suggest that more than a single binding mode can occur.
In order to further investigate the binding mode, fluorescence analyses were performed. Upon excitation at $\pi \rightarrow \pi^{*}$ transitions either in DMSO or in the presence CT-DNA, $\mathbf{1}$ did not emit luminescence. Hence, indirect evidence for the binding mode was examined by fluorescent displacement experiments, carried out with two different dyes: ethidium bromide (EB), a typical DNA intercalator and Hoechst $33258(\mathrm{H})$, a minor groove binder. It is known that EB interacts with CT-DNA in the intercalation mode with strong binding affinity. ${ }^{67}$ The extent of the fluorescence quenching of EB by competitive displacement from DNA is a measure of the strength of the interaction between the second molecule and DNA. ${ }^{68}$ Binding of EB to CTDNA was followed by excitation at $500 \mathrm{~nm}$ with a maximum in fluorescence at $600 \mathrm{~nm}$. The emission spectra of EB bound to CT-DNA in the absence and presence of $\mathbf{1}$ are given in Fig. 8. A continuous decrease was observed in fluorescence intensity at $600 \mathrm{~nm}$ for EB-CT-DNA with increasing concentration of $\mathbf{1}$ (up to $22 \mu \mathrm{M}$, see Experimental section). It was shown that the complex quenches the fluorescence probe with the maximal decrease in the fluorescence intensity of the EB-CT-DNA by $18 \%$, followed by saturation at a high concentration of $1(14 \mu \mathrm{M})$ (Fig. 8A and the inset). Fig. 8B shows that the obtained fluorescence quenching data gives a linear plot in accordance with the Stern-Volmer eqn (6) (see Experimental section). The fluorescence quenching constant $\left(K_{\mathrm{sv}}\right)$ value was calculated from the ratio of the slope to the intercept from the plot of $I_{0} / I$ versus $r$ (ratio of concentrations of complex 1 and CT-DNA, $r=[1] /[$ CTDNA]) as $K_{\mathrm{sv}}=1.802$. The observed saturation at high concentrations of $\mathbf{1}$ indicated that $\mathbf{1}$ quenches the fluorescence of EBCT-DNA by displacement of bound EB in a limited fraction of binding sites.

To further clarify the interaction of $\mathbf{1}$ with DNA, fluorescent displacement experiments with $\mathrm{H}$ dye were performed. $\mathrm{H}$ preferentially binds in the minor groove at A:T-rich sequences in BDNA at the edges of four to five contiguous base pairs with nanomolar affinity. ${ }^{69}$

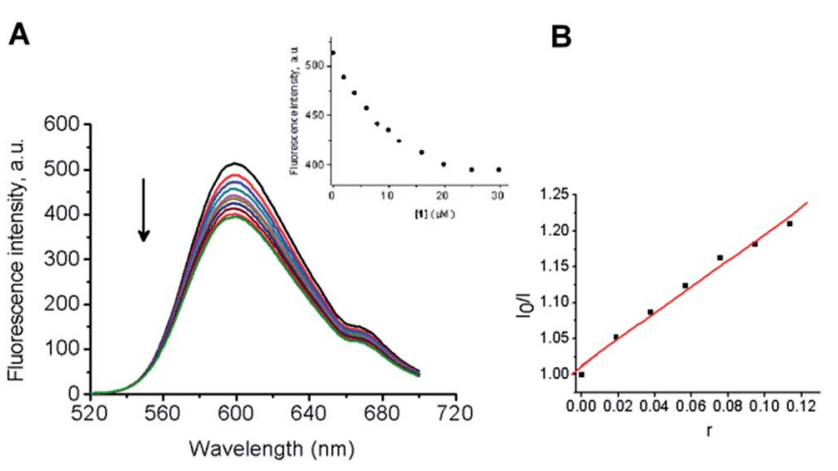

Fig. 8 Displacement of DNA-bound ethidium bromide (EB) by 1. (A) Emission spectra $\left(\lambda_{\text {ex }}=500 \mathrm{~nm}\right)$ of EB $\left(2.5 \times 10^{-5} \mathrm{M}\right)$ bound to CTDNA $\left(1 \times 10^{-4} \mathrm{M}\right.$, top line) and quenching of EB-CT-DNA system by 1 at increasing concentrations $\left(0\right.$ to $3 \times 10^{-5} \mathrm{M}$, curves from top to bottom). The arrow shows that fluorescence intensity decreased with increasing concentration of the complex. The inset demonstrates the saturation of binding. (B) Fluorescence quenching curves of EB bound to CT-DNA at $\lambda_{\max }=600 \mathrm{~nm}$ by $1 ; r=[1] /[C T-D N A]$. 
Also, an unspecific weaker binding at a high $[\mathrm{H}] /[\mathrm{DNAbp}]$ ratio has to be considered. ${ }^{70}$ Fig. 9A shows the characteristic emission spectrum of $\mathrm{H}$ when it is bound to CT-DNA. The addition of $\mathbf{1}$ to CT-DNA caused appreciable reduction in the fluorescence intensity of the H-CT-DNA system in a concentration dependent way. The quenching of H-CT-DNA showed an initial saturation at $10 \mu \mathrm{M}$ concentration of 1 (inset in Fig. 9A). It is important to note that the fluorescence intensity was reduced to nearly half of the initial value. The half-reciprocal plot of the quenching data according to the Stern-Volmer equation resulted in a linear plot with a quenching constant $K_{\mathrm{sv}}=6.43$. The value of quenching constant $K_{\mathrm{sv}}$ was calculated from the ratio of the slope to the intercept from the plot of $I_{0} / I$ versus $r(r=[\mathbf{1}] /$ [CT-DNA]) (Fig. 9B). With increasing concentration of $\mathbf{1}$, an additional decrease in fluorescence intensity was observed, followed by saturation in competitive displacement from the $\mathrm{H}-$ CT-DNA system.

The obtained results of the extent of the fluorescence quenching of EB by competitive displacement from the EB-CTDNA system and groove binder $\mathrm{H}$ from the $\mathrm{H}-\mathrm{CT}-\mathrm{DNA}$ system demonstrated that 1 non-selectively binds to DNA, exhibiting both binding modes. Comparing $K_{\mathrm{sv}}$ values for the quenching fluorescence intensity by displacement it may be concluded that 1 was more efficient as a groove binder than as an intercalator. The results are in agreement with UV-Vis spectrophotometry data.

Considering that the electrostatic interaction between the positively charged complex cation $\left[\mathrm{Zn}(\text { Hqasesc })_{2}\right]^{2+}$ and the negatively charged phosphate backbone may occur, with respect to the geometry of the complex, it can be concluded that optimal interaction can include partial intercalation of aromatic rings in the minor groove of the double helix of CTDNA. This mode of interaction with DNA by partial intercalation and specific minor groove binding was earlier described for bleomycins. $^{71}$

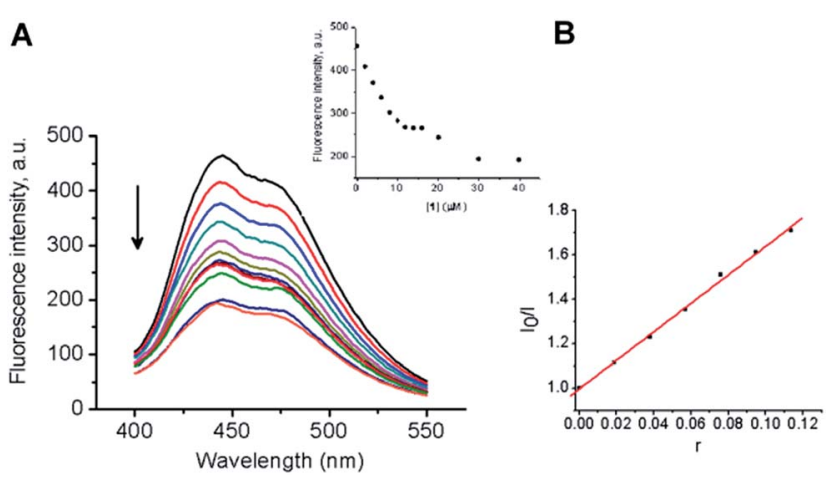

Fig. 9 Displacement of DNA-bound Hoechst $33258(\mathrm{H})$ by $1 .(\mathrm{A})$ Emission spectra $\left(\lambda_{\mathrm{ex}}=350 \mathrm{~nm}\right)$ of $\mathrm{H}\left(2.8 \times 10^{-5} \mathrm{M}\right)$ bound to CT-DNA $\left(1 \times 10^{-4} \mathrm{M}\right.$, top line) and quenching of $\mathrm{H}-\mathrm{CT}$-DNA system by 1 at increasing concentrations $\left(0\right.$ to $4 \times 10^{-5} \mathrm{M}$, curves from top to bottom). The arrow shows that fluorescence intensity decreased with increasing concentration of the complex. The inset demonstrates the saturation of binding. (B) Fluorescence quenching curves of $\mathrm{H}$ bound to CT-DNA at $\lambda_{\max }=440 \mathrm{~nm}$ by $1 ; r=[1] /[C T-D N A]$.

\section{Plasmid DNA interaction study}

The ability of 1 to cleave double-stranded plasmid DNA in the absence of any reducing agents was investigated using an electrophoretic analysis. As is shown in Fig. 10 (lane 1), plasmid pUC19 consists mainly of supercoiled form FI and nicked form FII. DMSO did not show any effect on plasmid DNA in the performed experimental conditions (Fig. 10, lane 2). Upon addition of an increasing concentration of 1 to the plasmid, a gradual diminishing of the supercoiled form FI and nicked form FII was observed (Fig. 10, lanes 3-6) and the forms disappeared at a much higher concentration of 1 (35 and $40 \mu \mathrm{M}$, lanes 7 and 8, respectively). The possible multimer forms with very slow mobility were observed (remained at the start of run). The generation of the multimer was concentration dependent indicating that 1 does not possess nuclease activity. A possible cause for aggregation can be formation of multiple hydrogen bonds between the complex cation and phosphate moieties in the plasmid DNA. Such multiple hydrogen bonds were observed in the crystal structure between the complex cation and perchlorate anion, which like phosphate, has a tetrahedral geometry.

\section{Interaction between 1 and human serum albumin (HSA)}

The interaction between 1 and HSA has been studied by UV-Vis and fluorescence spectroscopy. The UV-Vis spectra of HSA with increasing amounts of 1 showed a blue $\lambda_{\max }$ shift (from 280 to $271 \mathrm{~nm}$, Fig. 11A). The results indicate interaction between HSA and $\mathbf{1}$, leading to changes in the protein structure upon ligand binding. The changes in fluorescence emission spectra of HSA with increasing amount of $\mathbf{1}$ are shown on Fig. 11B.

As the concentration of $\mathbf{1}$ increases, the results may deviate from initial linearity due to an instrumental inner filter effect. ${ }^{72}$ In order to overcome this problem, absorbance was measured at excitation (280 $\mathrm{nm}$ ) and emission (340 nm) wavelengths, and fluorescence intensities corrected according to the Lakowicz

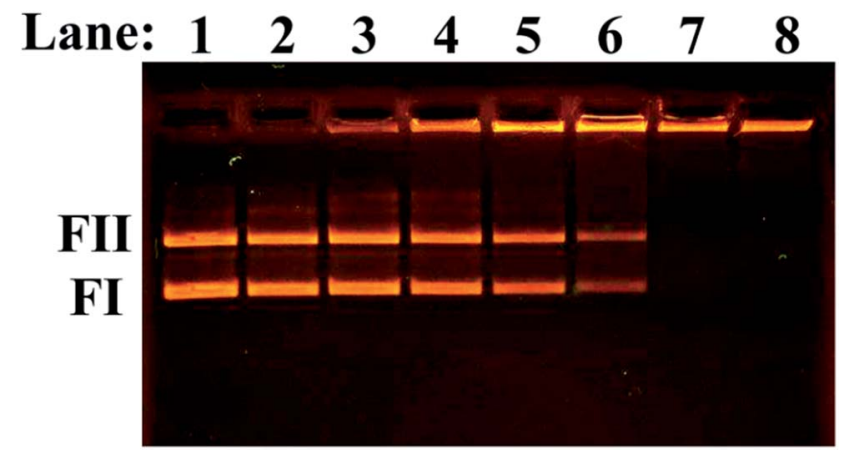

Fig. 10 Agarose gel electrophoresis of cleavage reaction of pUC19 by 1. The cleavage reaction was investigated by incubation for 90 min of $512 \mathrm{ng}$ plasmid in $20 \mu \mathrm{L}$ of $40 \mathrm{mM}$ bicarbonate buffer $(\mathrm{pH} 8.4)$ at $37^{\circ} \mathrm{C}$, with different concentrations of 1 . Lane 1 - control plasmid pUC19; lane 2 plasmid pUC19 with DMSO (20\% final); lanes 3-8: pUC19 with $0.015,0.02,0.025,0.03,0.035$, and $0.04 \mathrm{mM}$ concentration of 1 , respectively. 

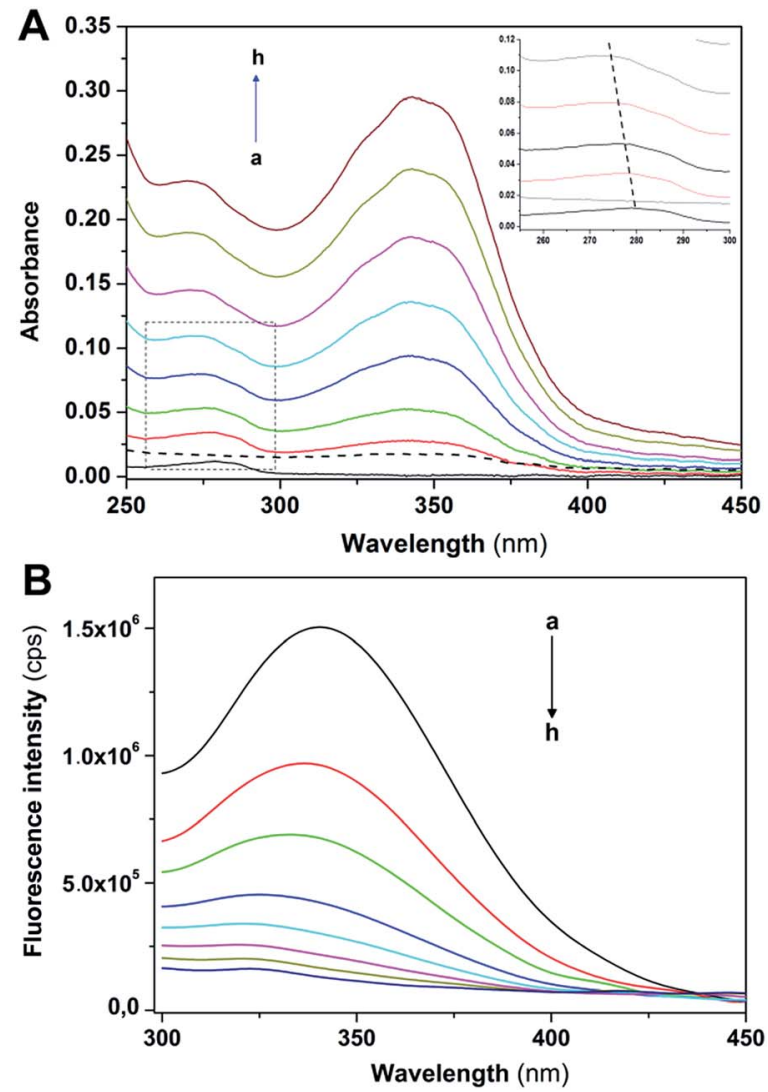

Fig. 11 Changes in UV-Vis absorption spectra (A) and fluorescence emission spectra (B) of HSA $\left(C=5 \times 10^{-7} \mathrm{M}\right)$ in PBS buffer $(1 \times \mathrm{PBS}, \mathrm{pH}$ 7.35) upon addition of 1 in the following concentrations $\left(\times 10^{-6} \mathrm{M}\right)$ : (a) 0.0 ; (b) 0.34; (c) 0.68; (d) 1.36; (e) 2.04; (f) 3.06; (g) 4.08; (h) 5.1. The UV-Vis absorption spectrum of pure complex $1\left(c=5 \times 10^{-7} \mathrm{M}\right)$ is represented with a dashed line; a magnified part of the original HSA spectrum around $\lambda_{\max }(280 \mathrm{~nm})$ is embedded, with blue shift indicated by a dashed line.

equation $^{73}$ given in the Experimental part. Corrected fluorescence intensities were used for further calculations.

Upon addition of an increasing amount of $\mathbf{1}$, a significant decrease of HSA fluorescence intensity (fluorescence quenching) is observed, as well as a blue shift of the wavelength of maximum emission $(340 \mathrm{~nm})$. This shift indicates that the microenvironment around Trp 214 is altered as the HSA-1 adduct is formed. In general, fluorescence quenching might be classified as static or dynamic. Dynamic quenching is highly dependent upon diffusion. Higher temperatures result in faster diffusion and hence larger values for bimolecular quenching constant. On the other hand, higher temperatures will typically result in the dissociation of weakly bound complexes, and therefore decrease the bimolecular quenching constant in a static process. Fluorescence quenching data were processed using the Stern-Volmer equation ${ }^{74}$ (for details see Experimental part) in order to obtain $K_{\mathrm{sv}}$ and $K_{\mathrm{q}}$, the Stern-Volmer quenching constant and the quenching rate constant of the protein, respectively (Fig. S16, ESI $\dagger$ ). As can be seen from Table $4, K_{\mathrm{sv}}$ decreases as temperature increases, indicating that the quenching mechanism is static. Another confirmation of the
Table 4 Results of Stern-Volmer plot at different temperatures (the average fluorescence lifetime $\tau_{0}=7.09 \mathrm{~ns}$ for HSA). $K_{\text {sv }}$ is obtained as a slope, while intercept is kept constant $(=1)$

\begin{tabular}{llll}
\hline & & $10^{14}$ & \\
& & & \\
& & & \\
293 & $10^{6} \times K_{\mathrm{sv}}\left(\mathrm{M}^{-1}\right)$ & $\left.\mathrm{s}^{-1}\right)$ & $r^{2}$ \\
298 & $2.01 \pm 0.04$ & 2.82 & 0.995 \\
310 & $1.91 \pm 0.04$ & 2.70 & 0.994 \\
\hline
\end{tabular}

static quenching mechanism is the value of $K_{\mathrm{q}}$, which is higher than the maximum scatter collision quenching constant value $\left(2 \times 10^{10} \mathrm{M}^{-1} \mathrm{~s}^{-1}\right) .^{75}$

The quenching process was additionally analyzed using a modified Stern-Volmer equation ${ }^{73}$ in order to obtain the effective quenching constant, $K_{\mathrm{a}}$, for the accessible fluorophores, and the fraction of accessible fluorophore $f_{\mathrm{a}}$. The results are shown in Fig. S17 (ESI $\dagger$ ) and in Table 5.

The $K_{\mathrm{a}}$ is inversely correlated with temperature, which is in accordance with $K_{\mathrm{sv}}$ temperature dependency.

Thermodynamic binding parameters, enthalpy $(\Delta H)$ and entropy change $(\Delta S)$, for binding of a small molecule to a protein can be calculated according to the Van't Hoff equation (given in the Experimental section) by measuring the binding constants at several temperatures. The results are shown in Fig. S18 (ESI $\dagger$ ) and in Table 5. According to Ross' view, ${ }^{76}$ signs and magnitudes of thermodynamic parameters for protein reactions can account for the main forces contributing to protein stability. From the thermodynamic stand-point, $\Delta H>$ 0 and $\Delta S>0$ implies a hydrophobic interaction, $\Delta H<0$ and $\Delta S<$ 0 reflects the van der Waals force or hydrogen bond formation and $\Delta H<0$ and $\Delta S>0$ suggest an electrostatic force. In our case, $\Delta H<0$ and $\Delta S>0$, indicates that the electrostatic forces are the main contributors to HSA-1 binding.

When small molecules bind independently to a set of equivalent sites of a protein, the equilibrium between free and bound molecules for the static quenching process is given by eqn (1): $:^{77}$

$$
\log \frac{F_{0}-F}{F}=\log K_{\mathrm{b}}+n \log [\mathrm{Q}]
$$

where $F_{0}$ and $F$ are the steady-state fluorescence intensities in the absence and presence of $1 ; K_{\mathrm{b}}$ is binding constant, $n$ is the number of binding sites and $[\mathrm{Q}]$ denotes the total concentration of quencher. Linear dependence is shown in Fig. S19 (ESI $\dagger$ ), and the results of linear fit are given in Table 6 . As the value of $n$ is close to 1 , it is suggested that 1 binds only to one binding site. The value of $K_{\mathrm{b}}$ is in the order of $10^{6}$. These results, along with the previously determined effective quenching constant $K_{\mathrm{a}}$, suggest that 1 strongly binds to HSA, so it can be effectively carried and stored in the human body.

Fluorescence resonance energy transfer (FRET) is a nondestructive spectroscopic method that can give information about the distance and relative orientation of the donor (Trp 214, D) and acceptor fluorophore (interacting molecule, A). The resonance transfer is more efficient when spectral overlap of 
Table 5 Results of binding of 1 to HSA obtained using the modified Stern-Volmer plot; thermodynamic parameters of binding are calculated using the Van't Hoff equation

\begin{tabular}{llllll}
\hline$T(\mathrm{~K})$ & $10^{6} \times K_{\mathrm{a}}\left(\mathrm{M}^{-1}\right)$ & $f_{\mathrm{a}}$ & $r^{2}$ & $\begin{array}{l}\Delta H \\
\left(\mathrm{~kJ} \mathrm{~mol}^{-1}\right)\end{array}$ & $\begin{array}{l}\Delta G \\
\left(\mathrm{~kJ} \mathrm{~mol}^{-1}\right)\end{array}$ \\
\hline 293 & $1.50 \pm 0.03$ & 0.973 & 0.999 & -11.02 & -34.64 \\
298 & $1.44 \pm 0.02$ & 0.972 & 0.998 & & -35.13 \\
310 & $1.18 \pm 0.01$ & 0.946 & 0.990 & & -36.03 \\
\end{tabular}

Table 6 Binding constants and the number of binding sites for the interaction of 1 with HSA at three temperatures

\begin{tabular}{llll}
\hline$T(\mathrm{~K})$ & $\log K_{\mathrm{b}}\left(\mathrm{M}^{-1}\right)$ & $n$ & $r^{2}$ \\
\hline 293 & $5.52 \pm 0.16$ & 0.897 & 0.995 \\
298 & $5.47 \pm 0.18$ & 0.892 & 0.994 \\
310 & $5.73 \pm 0.25$ & 0.958 & 0.990
\end{tabular}

donor emission and acceptor absorption is large (Fig. S20, ESI $\dagger$ ). The distance between D and A, $r$, could be calculated using energy transfer efficiency, $E$ (ref. 73) (for calculation details see Experimental part). We have calculated the overlap integral of the donor emission and the acceptor absorption spectra $\left(J=5.87 \times 10^{-15} \mathrm{M}^{-1} \mathrm{~cm}^{3}\right.$, Fig. S20, ESI $\left.\dagger\right)$, the energy transfer efficiency $(E=0.230)$, the Förster's distance at which energy transfer is $50 \%$ efficient $\left(R_{0}=2.385 \mathrm{~nm}\right)$, and the $\mathrm{D}-\mathrm{A}$ distance $(r=3.098 \mathrm{~nm})$. Since the distances between D and A are usually in the range $2-8 \mathrm{~nm}$, and the obtained $r$ value obeys the condition $0.5 R_{0}<r<1.5 R_{0},{ }^{73}$ we may conclude that the energy transfer between HSA and $\mathbf{1}$ is highly feasible process.

\section{Molecular docking of 1 with DNA and HSA}

To examine the binding of the zinc complex to DNA we used the

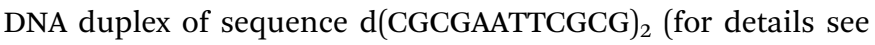
Experimental section). Molecular docking gave conformations binding to the minor and major groove, with slight preference for the minor groove (Fig. S21, ESI $\dagger$ ). Conformations with lowest binding energy correspond to the minor groove, and the difference between the lowest conformation and one bound to the major groove has a value of $0.1 \mathrm{kcal} \mathrm{mol}^{-1}$. No intercalating structures were found. The pattern of binding is presented in Fig. 12. The established interactions between $\mathbf{1}$ and DNA nucleotides are hydrogen bonds and aromatic interactions. This is expected, as $\mathbf{1}$ consists of coordinated groups that are hydrogen bond donors, particularly $\mathrm{NH}_{2}$ groups. Aromatic systems from zinc complexes tend to form $\mathrm{CH}-\pi$ interactions with DNA bases, along with selenium (Se- $\pi$ interactions), which can also form hydrogen bonds with bases. This is in accordance with the experimental results, as reported that $\mathbf{1}$ has more affinity to the minor groove than the major, and measurements showed no significant intercalation.

The $\mathrm{Zn}$ (II) complex was docked into previously identified binding sites of HSA (PDB IDs 2BXD and 4L9Q, see Experimental part for details), but obtained values of binding energies were not in accordance with experimental results, as they were too high or showing low binding affinity. Therefore we decided to search the whole conformational space of HSA (PDB ID 1BJ5) which gave an insight into other possible binding sites. According to the reported thermodynamic properties of ligand binding, we selected one conformation that was in the best accordance with the experiment, at the same time having the lowest binding energy, with value $E_{\mathrm{b}}=-36.38 \mathrm{~kJ} \mathrm{~mol}^{-1}$. As presented in Fig. 13, the main electrostatic interaction is formed with Glu 354, having in mind that the complex cation is +2 charged and electrostatic effects are transmitted through organic ligands coordinated to $\mathrm{Zn}$ (II). Also, nitrogen atoms of Arg 209 and Lys 351 and selenium atoms are sufficiently close,

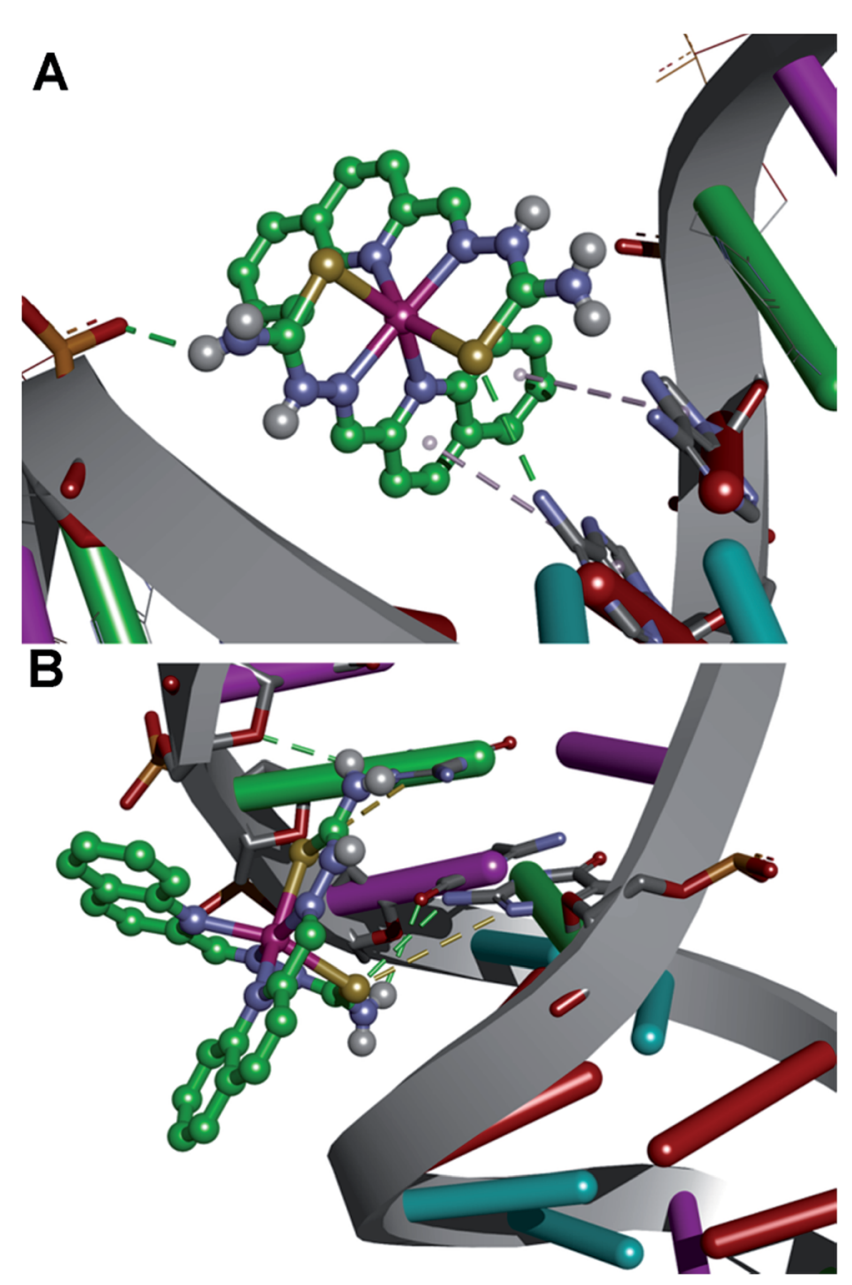

Fig. 12 Binding pattern of 1 to DNA with marked interactions: major groove (A) and minor groove (B). Color code: green - hydrogen bonds; grey - aromatic interactions; dark yellow - selenium $-\pi$ interactions. 


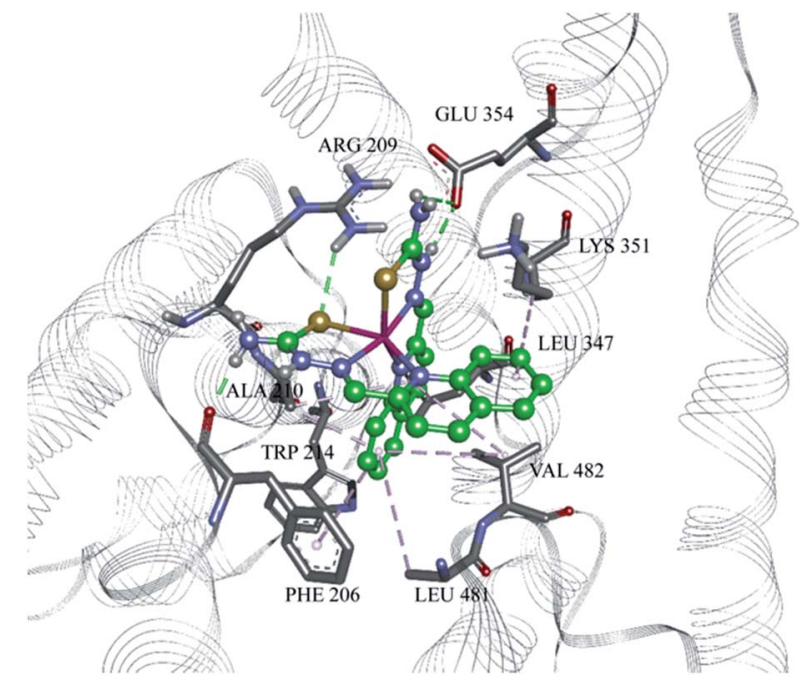

Fig. 13 The $\mathrm{Zn}(॥)$ complex in the binding site of HSA (PDB ID 1BJ5), with marked amino acid residues and interactions. Green: hydrogen bonds; grey: hydrophobic/aromatic interactions.

so the electrostatic interaction with partially positive hydrogen atoms on the residues cannot be neglected, and this is in accordance with the reported $\Delta H<0$. The rest of the interactions are of hydrophobic type, $\mathrm{CH}-\pi$ and aromatic, including interaction of residues Leu 347, Phe 206, Ala 210, Val 482, Leu 481 , and aliphatic chain of Lys 351 with aromatic rings of the ligand. This confirms the reported $\Delta S>0$ value. Also, the reported binding site is not far away from the earlier reported binding site II ${ }^{78}$ as it is close to Trp 214 (Fig. S22, ESI $\dagger$ ). The interactions and distances with the ligand are presented in Table S2 (ESI $\dagger$ ). According to the docking site results, binding affinity values and interactions, it can be concluded that this can be a binding site for the reported compound, and its high affinity to HAS can be explained.

\section{Conclusions}

A novel zinc(II) complex with a 2-quinolinecarboxaldehyde selenosemicarbazone ligand was synthesized and characterized. Investigation of biological activity shows that both compounds are strong apoptosis inducers in THP- 1 cells. The apoptotic induction is concentration-dependent and coincides with an arrest at the $\mathrm{S}$ phase of mitotic division, indicating that Hqasesc and 1 interfere with DNA replication. Results of DNA binding and DNA docking experiments confirm our hypothesis, revealing that 1 not only selectively binds to DNA, but with a higher affinity for the minor groove, with no significant intercalation. Therefore, the lack of caspase- 8 and -9 activation in THP-1 cells treated with $\mathbf{1}$ is consistent since apoptosis could be triggered here by caspase- 2 cascade after inhibited DNA replication. On the other hand, both compounds display less activity on the AsPC-1 cell line, which one could expect since those cells are mainly CSCs, being non differentiated and so more resistant to most conventional therapeutics. While Hqasesc in AsPC-1 cells induces apoptosis only at the highest applied concentration, treatment with 1 shows a concentrationdependent apoptotic response, obviously not induced by DNA drug interaction, considering that treated cells are arrested in the G1-to-S phase, accompanied by an extensive caspase-8 and -9 activation. These results indicate that Hqasesc and $\mathbf{1}$ display cell phenotype specific activity, which is a desirable characteristic that might signify cytotoxicity on a wide spectrum of cancer types. Finally, high affinity of $\mathbf{1}$ for HSA implies a possible pharmacokinetic property. The unbound fraction of the drug in plasma may be the active form, also subjected to metabolic transformation and excretion. The HSA-bound fraction of the drug may serve as a depository, slowly releasing it as unbound active form. A high percentage of HSA-bound drug will then prolong its half-life, reducing its volume of distribution, and thus avoid possible interactions with other drugs that compete for binding to HSA.

\section{Experimental section}

\section{Reagents and instrumentation}

Selenosemicarbazide (98\%) was obtained from Acros Organics (BVBA, Geel, Belgium). 2-Quinolinecarboxaldehyde and zinc perchlorate hexahydrate were obtained from Aldrich (SigmaAldrich Chemie GmbH, Steinheim, Germany). All solvents (reagent grade) were obtained from commercial suppliers and used without further purification.

Elemental analyses (C, H, N) were performed by the standard micromethods using the ELEMENTAR Vario EL III CHNS/O analyzer. IR spectra were recorded on a Thermo Scientific Nicolet 6700 FT-IR spectrophotometer by the Attenuated Total Reflection (ATR) technique in the region $4000-350 \mathrm{~cm}^{-1}$. Abbreviations used for IR spectra: vs, very strong; s, strong; m, medium; w, weak. Molar conductivity measurements were performed at ambient temperature $(298 \mathrm{~K})$ on a Crison Multimeter MM41. NMR spectral assignments and structural parameters were obtained by combined use of ${ }^{1} \mathrm{H}$ homonuclear spectroscopy (2D COSY and NOESY) and multinuclear protondetected spectroscopy (2D HSQC, 2D HMBC). The NMR spectra were performed on a Bruker Avance 500 equipped with broad-band direct probe. Chemical shifts are given on $\delta$ scale relative to tetramethylsilane (TMS) as internal standard for ${ }^{1} \mathrm{H}$ and ${ }^{13} \mathrm{C}$. Abbreviations used for NMR spectra: s, singlet; dd, doublet of doublets; ddd, double double doublet. Cyclic voltammetric measurements were performed using an electrochemical system $\mathrm{CH}$ Instruments (USA). UV-Vis spectra for acidity constant determination were recorded on a Thermo Scientific Evolution 60S spectrophotometer (Thermo Fisher Scientific Inc, Waltham, Massachusetts, USA) in 250-500 nm range. $\mathrm{pH}$ values were measured using a CRISON pH-Burette 24 2S equipped with a CRISON 5029 micro-combined pH electrode (CRISON INSTRUMENTS, S.A. Spain). For DPPH scavenging activity, absorbance at $517 \mathrm{~nm}$ was measured using a Thermo Scientific Appliskan. Pro-apoptotic activity was determined on a Guava EasyCyte ${ }^{\mathrm{TM}}$ micro-capillary flow cytometer (EMD Millipore, Darmstadt, Germany) using the InCyte ${ }^{\circledR}$ software package (EMD Millipore, Cat. no. 0500-4120). UV-Vis spectra for DNA binding studies were recorded on a UV-1800 Shimadzu UV- 
Visible spectrometer operating from 200 to $800 \mathrm{~nm}$ in $1.0 \mathrm{~cm}$ quartz cells, while for fluorescence measurements a Thermo Scientific Lumina Fluorescence spectrometer (Finland) equipped with a $150 \mathrm{~W}$ xenon lamp was used. A Submarine Mini-gel Electrophoresis Unit (Hoeffer HE 33) with an EPS 300 power supply was used for DNA cleavage studies. The stained gel was illuminated under a UV transilluminator Vilber-Lourmat (France) at $312 \mathrm{~nm}$ and photographed with a Nikon Coolpix P340 Digital Camera through filter Deep Yellow 15 (Tiffen, USA). UV-Vis spectra for HSA binding studies were recorded on a Thermo Scientific Evolution 60S UV-Vis spectrophotometer, using a quartz cell with $1.0 \mathrm{~cm}$ path length, while fluorescence measurements were performed on a spectrofluorometer Fluoromax-4 Jobin Yvon (Horiba Scientific, Japan), equipped with a Peltier element for temperature control and a magnetic stirrer for cuvette, using a quartz cell with $1 \mathrm{~cm}$ path length.

\section{Synthesis of Hqasesc}

The ligand was synthesized according to the reported procedure. ${ }^{14}$ Single crystals suitable for X-ray analysis were obtained by recrystallization of the crude product from EtOH. The chemical structure of Hqasesc was confirmed by elemental analysis, IR and NMR spectroscopy. These data are in good agreement with the data previously reported..$^{14}$

\section{Synthesis of $\left[\mathrm{Zn}\left(\mathrm{Hqasesc}_{2}\right]\left(\mathrm{ClO}_{4}\right)_{2} \cdot \mathrm{EtOH}(1)\right.$}

Into the solution of 2-quinolinecarboxaldehyde $(0.15 \mathrm{~g}, 0.96$ $\mathrm{mmol}$ ) and selenosemicarbazide $(0.13 \mathrm{~g}, 0.96 \mathrm{mmol})$ in EtOH $(20 \mathrm{~mL}), \mathrm{Zn}\left(\mathrm{ClO}_{4}\right)_{2} \cdot 6 \mathrm{H}_{2} \mathrm{O}(0.18 \mathrm{~g}, 0.48 \mathrm{mmol})$ was added. The reaction mixture was refluxed for $30 \mathrm{~min}$ and cooled to ambient temperature. Dark red crystals of $\mathbf{1}$ were obtained from the ethanolic solution, filtered off and washed with cold ethanol and ether. Yield: $0.28 \mathrm{~g}$ (66\%). Found: C, 33.5; H, 3.1; N, 12.9. Calc. for $\mathrm{C}_{24} \mathrm{H}_{26} \mathrm{Cl}_{2} \mathrm{~N}_{8} \mathrm{O}_{9} \mathrm{Se}_{2} \mathrm{Zn}: \mathrm{C}, 33.3 ; \mathrm{H}, 3.0 ; \mathrm{N}, 13.0 \%$. IR (ATR), $\nu_{\text {max }} / \mathrm{cm}^{-1}$ : 3434m $\left(\mathrm{NH}_{2}\right), 3297 \mathrm{vs}(\mathrm{NH}), 3183 \mathrm{vs}(\mathrm{NH})$, 3077s $\left(\mathrm{NH}_{2}\right), 1617 \mathrm{~s}(\mathrm{C}=\mathrm{N}), 1578 \mathrm{~s}(\mathrm{NH}), 1511 \mathrm{~m}(\mathrm{CH}), 1100 \mathrm{vs}$ $\left(\mathrm{ClO}_{4}{ }^{-}\right) . \Lambda_{\mathrm{M}}\left(1 \times 10^{-3} \mathrm{M}, \mathrm{EtOH}\right): 72.0 \Omega^{-1} \mathrm{~cm}^{2} \mathrm{~mol}^{-1} \cdot{ }^{1} \mathrm{H} \mathrm{NMR}$ (500 MHz, DMSO, TMS) [ppm] $\delta: 12.56$ (s, 1H, N3H), 9.28 (s, 1H, $\mathrm{N} 4 \mathrm{Hb}), 9.14$ (s, 1H, N4Ha), $8.86\left(\mathrm{~d}, 1 \mathrm{H}, \mathrm{C} 4 \mathrm{H},{ }^{3} J_{4,3}=8.8 \mathrm{~Hz}\right), 8.72$ $\left(\mathrm{d}, 1 \mathrm{H}, \mathrm{C} 3 \mathrm{H},{ }^{3} \mathrm{~J}_{3,4}=8.8 \mathrm{~Hz}\right), 8.38(\mathrm{~s}, 1 \mathrm{H}, \mathrm{C} 9 \mathrm{H}), 8.19(\mathrm{dd}, 1 \mathrm{H}, \mathrm{C} 5 \mathrm{H}$, $\left.{ }^{3} J_{5,6}=7.7 \mathrm{~Hz},{ }^{4} J_{5,7}=1.1 \mathrm{~Hz}\right), 8.13\left(\mathrm{dd}, 1 \mathrm{H}, \mathrm{C} 8 \mathrm{H},{ }^{3} J_{8,7}=8.5 \mathrm{~Hz}\right.$, $\left.{ }^{4} J_{8,6}=1.3 \mathrm{~Hz}\right), 8.01\left(\mathrm{ddd}, 1 \mathrm{H}, \mathrm{C} 7 \mathrm{H},{ }^{3} J_{7,8}=8.5 \mathrm{~Hz},{ }^{3} J_{7,6}=7.0 \mathrm{~Hz}\right.$, ${ }^{4} J_{7,5}=1.1 \mathrm{~Hz}$ ), $7.83\left(\mathrm{ddd}, 1 \mathrm{H}, \mathrm{C} 6 \mathrm{H},{ }^{3} J_{6,5}=7.7 \mathrm{~Hz},{ }^{3} J_{6,7}=7.0 \mathrm{~Hz}\right.$, $\left.{ }^{4} J_{6,8}=1.3 \mathrm{~Hz}\right) \cdot{ }^{13} \mathrm{C}$ NMR (126 MHz, DMSO, TMS) [ppm] $\delta: 175.86$ (C10), 151.04 (C2), 142.42 (C4), 140.71 (C8a), 136.57 (C9), 133.28 (C7), 128.98 (C6), 128.77 (C5), 128.12 (C4a), 123.27 (C8), 119.23 (C3). Numbering of atoms used in NMR is given in Scheme S1 $(\mathrm{ESI} \dagger)$.

Direct syntheses of $\mathbf{1}$ starting from zinc perchlorate and Hqasesc in EtOH afforded an identical product as the template synthesis, but in a slightly lower yield.

\section{X-ray crystallography}

Single crystal X-ray diffraction was performed on an Oxford Diffraction Gemini S kappa geometry diffractometer, equipped with Mo K $\alpha$ radiation from a sealed tube source, and a Sapphire
CCD detector. Data collection strategy calculation, data reduction, cell refinement and absorption correction were performed with the CRYSALISPRO. ${ }^{79}$ The structure was solved using SHELXT, ${ }^{\mathbf{8 0}}$ and refined with anisotropic displacement parameters for all non-hydrogen atoms using SHELXL-2014. ${ }^{81}$ Program SHELXLE $^{82}$ was used as graphical user interface for structure solution and refinement procedures. Hydrogen atoms bonded to carbon atoms were introduced in idealized positions and refined using a riding model. Hydrogen atoms bonded to nitrogen atoms were located by difference Fourier synthesis, and refined using distance restraints with $U_{\text {iso }}$ approximated by $1.2 U_{\text {eq }}$ of the parent atoms in Hqasesc, whilst their free isotropic refinement was performed in 1. Hydroxyl group of the EtOH molecule in 1 showed positional disorder, which was modeled by refining occupational parameters, and applying distance restraints. Structure was validated using PLATON, ${ }^{\mathbf{8 3}}$ and Cambridge Structural Database (CSD) (v. 5.36, updates Nov. 2014) ${ }^{45}$ using MERCURY CSD. ${ }^{44}$

Crystallographic data for Hqasesc and $\mathbf{1}$ have been deposited with the Cambridge Crystallographic Data Centre as Supplementary publication no. CCDC 1413656 and 1413657, $\dagger$ respectively.

\section{Cyclic voltammetry}

The cell $(10 \mathrm{~mL})$ consisted of a three-electrode system, glassy carbon electrode (inner diameter of $3 \mathrm{~mm}$; $\mathrm{CHI} 104$ ) an $\mathrm{Ag} / \mathrm{AgCl}$ (saturated $\mathrm{KCl}$ ) reference electrode and $\mathrm{Pt}$ counter electrode. The potential was swept over the range from -2.0 to $+1.2 \mathrm{~V}(v s$. $\mathrm{Ag} / \mathrm{AgCl}$ ) at scan rate of $100 \mathrm{mV} \mathrm{s}^{-1}$. Measurements were performed at room temperature with deaeration of solutions by passing a stream of nitrogen through the solution for $5 \mathrm{~min}$ prior to the measurement and then maintaining a blanket atmosphere of nitrogen over the solution during the measurement. The potentials were measured in $0.10 \mathrm{M}\left[n-\mathrm{Bu}_{4} \mathrm{~N}\right] \mathrm{PF}_{6} /$ $\mathrm{DMSO}$, and are quoted relative to $\mathrm{Ag} / \mathrm{AgCl}$ reference electrode.

\section{Determination of Hqasesc acidity constants}

Acidity constants of Hqasesc were determined by spectrophotometric titration at $T=298 \pm 1 \mathrm{~K}$. The working solution $(c=3.1$ $\times 10^{-5} \mathrm{M}$ ) was prepared by dissolving an accurately weighed dried substance in $5.00 \mathrm{~mL}$ of DMSO; $10 \mathrm{mM}$ phosphate buffer $(\mathrm{pH}=1.77, I=0.1 \mathrm{M} \mathrm{NaCl})$ was added up to $100.00 \mathrm{~mL}$. The $\mathrm{pH}$ value was adjusted to 1.65 with conc. HCl. Small volume increments of $1 \mathrm{M} \mathrm{KOH}$ were added stepwise, until $\mathrm{pH} 11.91$ was reached (total volume change at the end of the titration was lower than $2 \%$ ). The $\mathrm{pH}$ value was continuously measured during the titration and UV-Vis spectra recorded after $\mathrm{pH}$ value equilibration. The UV-Vis spectra were recorded against the phosphate buffer as a blank. The $\mathrm{pH}$ electrode was calibrated by standard CRISON buffer solutions ( $\mathrm{pH} 4.01,7.00$, and 9.21). Acidity constants for Hqasesc were calculated according to transformed forms of classical spectrophotometric equations ${ }^{\mathbf{4 3}}$ which give linear dependence:

$$
A=A_{\mathrm{H}_{2} \mathrm{~A}^{+}}+\frac{A_{\mathrm{HA}}-A}{\left[\mathrm{H}_{3} \mathrm{O}^{+}\right]} \times K_{\mathrm{a} 1}
$$


or

$$
\begin{gathered}
\left(A-A_{\mathrm{HA}}\right) \times 10^{\mathrm{pH}}=\frac{A_{\mathrm{H}_{2} \mathrm{~A}^{+}}}{K_{\mathrm{a} 1}}-\frac{1}{K_{\mathrm{a} 1}} A \\
A=A_{\mathrm{A}^{-}}+\left(A_{\mathrm{HA}}-A\right) \times\left[\mathrm{H}_{3} \mathrm{O}^{+}\right] \times \frac{1}{K_{\mathrm{a} 2}}
\end{gathered}
$$

or

$$
\left(A-A_{\mathrm{HA}}\right) \times 10^{-\mathrm{pH}}=K_{\mathrm{a} 2} \times A_{\mathrm{A}^{-}}-K_{\mathrm{a} 2} \times A
$$

where $A$ represents absorbance of certain species $\left(\mathrm{H}_{2} \mathrm{~A}^{+}, \mathrm{HA}\right.$, or $\mathrm{A}^{-}$) labeled as subscripts, and $K_{\mathrm{a} 1}$ and $K_{\mathrm{a} 2}$ represent the first and second dissociation constant of Hqasesc, respectively.

\section{Free radical scavenging antioxidant assay (DPPH method)}

The proton donating ability was assayed using a protocol for the determination of radical scavenging activity. ${ }^{52}$ Compounds were dissolved in pure DMSO and were diluted into ten different concentrations. Commercially available free radical DPPH was dissolved in methanol at a concentration of $6.58 \times 10^{-5} \mathrm{M}$. Into a 96-well microplate, $140 \mu \mathrm{L}$ of DPPH solution was loaded and $10 \mu \mathrm{L}$ DMSO solution of the tested compounds was added, or pure DMSO $(10 \mu \mathrm{L})$ as the control. The microplate was incubated for $30 \mathrm{~min}$ at $298 \mathrm{~K}$ in the dark and the absorbance was measured at $517 \mathrm{~nm}$. All the measurements were carried out in triplicate. The scavenging activity of the compounds was calculated using the eqn (4):

$$
\text { Scavenging activity }(\%)=\frac{A_{\text {control }}-A_{\text {sample }}}{A_{\text {control }}} \times 100
$$

where $A_{\text {sample }}$ and $A_{\text {control }}$ refer to the absorbances at $517 \mathrm{~nm}$ of DPPH in the sample and control solutions, respectively.

$\mathrm{IC}_{50}$ values were calculated from the plotted graph of scavenging activity against the concentrations of the samples. $\mathrm{IC}_{50}$ is defined as the total antioxidant concentration necessary to decrease the amount of the initial DPPH radical by $50 \% . \mathrm{IC}_{50}$ was calculated for all compounds based on the percentage of DPPH radicals scavenged. Ascorbic acid was used as the reference compound (positive control) with concentrations 50 to 500 $\mu \mathrm{g} \mathrm{mL}^{-1}$.

\section{Cell cultures}

Acute monocytic leukemia cell line (THP-1, ATCC® TIB-202) and pancreatic adenocarcinoma cell line (AsPC-1, ATCC $®$ CRL-1682) were maintained in RPMI-1640 (Life Technologies, 11875-093) and DMEM high glucose (Sigma-Aldrich, D5796) cell culture media, respectively. Both media were supplemented with $10 \%(\mathrm{v} / \mathrm{v})$ fetal bovine serum (FBS, Gibco, Cat. no. 16000036) and $1 \%(\mathrm{v} / \mathrm{v})$ penicillin-streptomycin (10 000 units per $\mathrm{mL}$ and $10000 \mu \mathrm{g} \mathrm{mL}^{-1}$, Gibco, Cat. no. 15140-130). Cells were kept at $37^{\circ} \mathrm{C}$ in an atmosphere containing $5 \%(\mathrm{v} / \mathrm{v}) \mathrm{CO}_{2}$ during their exponential growth and during the course of experimental treatments.

The ligand Hqasesc and 1 were initially dissolved in DMSO to the stock concentration of $20 \mathrm{mM}$, whereas CDDP was dissolved in saline to the stock concentration of $5 \mathrm{mM}$. Further dilutions to the experimental concentrations applied on the cells have been done with RPMI-1640 or DMEM media immediately before each experiment, thus the final concentration of DMSO with cells treated with the highest applied concentration was $0.5 \%$ (v/v).

\section{Determination of pro-apoptotic activity}

THP-1 and AsPC-1 cells were seeded in 96 flat bottom well plates (Corning ${ }^{\circledR}$ Costar ${ }^{\circledR}$, Cat. no. CLS3596) in a volume of $0.1 \mathrm{~mL}$, at a density of 10000 per well. Since the THP-1 cells grow in suspension, experimental treatments were started within $2 \mathrm{~h}$ after cell seeding, while plates with seeded AsPC-1 cells were left overnight to settle. Investigated compounds were added in a range of six concentrations. As controls, non-treated cells, cells treated with $0.5 \%$ DMSO, and cells treated with Celastrol (Enzo Life Sciences, Cat. no. ALX-350-332-M025) at $50 \mu \mathrm{M}$ concentration were used.

After $24 \mathrm{~h}$ of incubation, THP-1 cells were centrifuged at an RCF of $450 \times g$ for $10 \mathrm{~min}$, supernatants were discarded, and 0.1 $\mathrm{mL}$ of PBS was added to each well. Plates were placed on a plate shaker for $3 \mathrm{~min}$, afterwards Annexin-V-FITC (ImmunoTools, Cat. no. 31490013) and propidium iodide (PI, MiltenylBiotec, Cat. no. 130-093-233) were added in a volume of $3 \mu \mathrm{L}$ per well, respectively, and incubated for $15 \mathrm{~min}$ in the dark before cytometry analysis. Post incubation manipulation with AsPC-1 cells included trypsinization $(200 \mu \mathrm{L}$ of trypsin per well, Sigma-Aldrich, Cat. no. T3924). Subsequent steps with addition of PBS, Annexin-V and PI were the same as for THP-1 cells. Plates were analyzed on a flow cytometer. Cells were classified according to Annexin-V and PI labeling into viable (non-stained cells), pre-apoptotic cells (stained with Annexin-V only), cells in late phases of apoptosis (double stained cells), and necrotic cells (stained with PI only). After this read-out was ended, the remaining cells were fixed in ethanol overnight at $4{ }^{\circ} \mathrm{C}$, and afterwards stained with FxCycle ${ }^{\mathrm{TM}}$ PI/RNAse Staining solution (Molecular Probes, Cat. no. F10797), and analyzed as described previously. ${ }^{84}$

\section{Calculation of $\mathrm{ED}_{50}$ concentration}

Separately for THP-1 and AsPC-1 cells, the percent of Annexin-V labeled cells for each investigated concentration of compounds were summarized and the maximum apoptotic response was normalized to $100 \%$. The percent of apoptosis read-out for other concentrations were calculated as a proportion of the highest response. Such scaled apoptotic outcomes were plotted against concentrations and $\mathrm{ED}_{50}$ concentration was calculated using the asymmetric sigmoidal curve five-parameter logistic equation (GraphPad Prism 6 software). The determined ED $_{50}$ concentrations of both compounds were applied in further steps of this investigation.

\section{Inhibition of caspase activity}

THP-1 and AsPC-1 cells were treated with investigated compounds at the $\mathrm{ED}_{50}$ concentration for $6 \mathrm{~h}$ with or without pan-caspase inhibitor Z-VAD-fmk (Promega, Cat. no. G7232). Previously, the proper concentration of Z-VAD-fmk that is non- 
toxic to cells during $6 \mathrm{~h}$ of incubation was determined $(10 \mu \mathrm{M}$ and $20 \mu \mathrm{M}$ for THP-1 and AsPC-1 cell lines, respectively). As controls, non-treated cells, cells treated with Z-VAD-fmk only, and cells treated with $\mathrm{ED}_{50}$ concentrations only were used. After the incubation period had ended, plates with THP-1 and AsPC-1 treated cells were stained with Annexin-V/PI as described above, and analyzed on a Guava EasyCyte ${ }^{\mathrm{TM}}$ cytometer. The percent of apoptosis inhibited by Z-VAD-fmk co-treatment was determined by the formula: apoptosis inhibition, $\%=[1-$ (\% of apoptosis in $\mathrm{A} / \%$ of apoptosis in $\mathrm{B}$ ) $] \times 100$, where $\mathrm{A}$ is the sample treated with both ED50 and Z-VAD-fmk, while B is the corresponding sample treated with $\mathrm{ED}_{50}$ only.

\section{Evaluation of caspase-8 and -9 activities}

THP-1 and AsPC1 cells were treated with the investigated compounds at the $\mathrm{ED}_{50}$ concentration for $6 \mathrm{~h}$. Afterwards the activity of caspase- 8 and -9 were assayed by means of a Guava Caspase 9 SR and a Caspase 8 FAM kit (EMD Millipore, Cat. no. 4500-0640), following the instructions of the manufacturer. In acquired data cells were discriminated according to expression of green fluorescence (caspase-8), yellow fluorescence (caspase9 ), or red fluorescence (7-AAD) as the following: live cells (not stained with either caspase nor 7-AAD), mid-stage apoptotic cells (cells stained with either caspase 8 or 9, but negative to 7AAD), late stage apoptotic cells (cells stained with either of caspase 8 or 9 and with 7-AAD), necrotic cells (cells not stained with either caspase 8 nor 9 , but positive for 7-AAD).

\section{DNA binding experiments}

Calf thymus DNA (lyophilized, highly polymerized, obtained from Serva, Heidelberg) (CT-DNA) was dissolved in Tris buffer (10 mM Tris-HCL pH 7.9) overnight at $4{ }^{\circ} \mathrm{C}$. This stock solution (2.86 $\mathrm{mg} \mathrm{mL}^{-1}$ ) was stored at $4{ }^{\circ} \mathrm{C}$ and was stable for several days. A solution of CT-DNA in water gave a ratio of UV absorbance at 260 and $280 \mathrm{~nm}, A_{260} / A_{280}$ of 1.89-2.01, indicating that the DNA was sufficiently free of protein. The concentration of DNA (2.86 $\mathrm{mg} \mathrm{mL}^{-1}$ ) was determined from the UV absorbance at $260 \mathrm{~nm}$ using the extinction coefficient $\varepsilon_{260}=6600 \mathrm{M}^{-1}$ $\mathrm{cm}^{-1} .{ }^{85}$ The complex was dissolved in DMSO in concentrations of $10 \mathrm{mM}$. This solution was used as stock solution.

UV-visible measurements. Reaction mixtures $(1 \mathrm{~mL}$ in 40 $\mathrm{mM}$ bicarbonate buffer, $\mathrm{pH}$ 8.4) consisting of 1,3 and $6 \mu \mathrm{L}$ of the stock solution of 1 and $10 \mu \mathrm{L}$ of the solution of CT-DNA were incubated at $37{ }^{\circ} \mathrm{C}$ for $90 \mathrm{~min}$ with occasional vortexing. The absorbance titrations were performed at a fixed concentration of $1(30 \mu \mathrm{M})$ and gradually increasing the concentration of double stranded CT-DNA $(2.5,5,7.5,10,12.5,15,17.5$ and 20 $\mu \mathrm{L})$. The absorbance at 260 and $344 \mathrm{~nm}$ was monitored for each concentration of DNA. The binding constant $K_{\mathrm{b}}$ was determined using eqn (5): ${ }^{86}$

$$
\left.\varepsilon_{\mathrm{f}}\right)^{-1}[\mathrm{DNA}] \times\left(\varepsilon_{\mathrm{a}}-\varepsilon_{\mathrm{f}}\right)^{-1}=[\mathrm{DNA}] \times\left(\varepsilon_{\mathrm{b}}-\varepsilon_{\mathrm{f}}\right)^{-1}+K_{\mathrm{b}}{ }^{-1} \times\left(\varepsilon_{\mathrm{b}}-\right.
$$

where $\varepsilon_{\mathrm{a}}, \varepsilon_{\mathrm{f}}, \varepsilon_{\mathrm{b}}$ are absorbance/[1], extinction coefficient of the free complex and the extinction coefficient of the bound compound, respectively. A plot of $[\mathrm{DNA}] /\left(\varepsilon_{\mathrm{a}}-\varepsilon_{\mathrm{f}}\right)$ versus [DNA] gave a slope and intercept equal to $1 /\left(\varepsilon_{\mathrm{a}}-\varepsilon_{\mathrm{f}}\right)$ and $\left(1 / K_{\mathrm{b}}\right)\left(1 /\left(\varepsilon_{\mathrm{b}}-\right.\right.$ $\left.\varepsilon_{\mathrm{f}}\right)$ ), respectively. The binding constant $K_{\mathrm{b}}$ was calculated from the ratio of the slope to the intercept. The percentage of hyperchromicity or hypochromicity for the CT-DNA/[1] was determined from: $\left(\varepsilon_{\mathrm{a}}-\varepsilon_{\mathrm{f}}\right) / \varepsilon_{\mathrm{f}} \times 100$.

Fluorescence measurements. The competitive interactions of 1 and the fluorescence probe (ethidium bromide - EB and Hoechst 33258 - H) with CT-DNA have been studied by measuring the change of fluorescence intensity of the probeDNA solution after addition of $\mathbf{1}$. Reaction mixtures containing $100 \mu \mathrm{M}$ of CT-DNA (calculated per phosphate) in $1 \mathrm{~mL}$ of 40 $\mathrm{mM}$ bicarbonate solution ( $\mathrm{pH}$ 8.4) were pretreated with $1 \mu \mathrm{L}$ of the probe solution $(25 \mu \mathrm{M}$ of $\mathrm{EB}$ and $28 \mu \mathrm{M}$ of $\mathrm{H}$ at final concentrations) for $20 \mathrm{~min}$ and the mixture was analyzed by fluorescence measurement. Then gradually increasing concentrations of the complex $(2,4,6,810,12,16,20,25,30$ and $40 \mu \mathrm{M}$ final concentrations) were successively added and the change in the fluorescence intensity was measured. The slits on the excitation and emission beams were fixed at $10 \mathrm{~nm}$. All measurements were performed by excitation at $500 \mathrm{~nm}$ in the range 520$700 \mathrm{~nm}$ for EB and by excitation at $350 \mathrm{~nm}$ in the range 390-600 $\mathrm{nm}$ for $\mathrm{H}$. The control was EB-CT-DNA solution and H-CT-DNA solution, respectively. The complex did not have fluorescence under the applied conditions. The obtained fluorescence quenching data were analyzed according to the Stern-Volmer eqn (6): ${ }^{73}$

$$
\frac{I_{0}}{I}=1+K_{\mathrm{sv}}[\mathrm{Q}]
$$

where $I_{0}$ and $I$ represent the fluorescence intensities of probeCT-DNA in the absence and presence of $\mathbf{1}$, respectively, $K_{\mathrm{sv}}$ is the quenching constant and [Q] is the concentration ratio of the complex to DNA ([1]/[CT-DNA]). The $K_{\mathrm{sv}}$ value is calculated from the ratio of the slope to the intercept from the plot of $I_{0} / I$ versus [Q].

\section{DNA cleavage experiments}

For DNA cleavage experiments the plasmid pUC19 (2686 bp, purchased from Sigma-Aldrich, USA) was prepared by its transformation in chemically competent cells Escherichia coli strain XL1 blue. Amplification of the clone was done according to the protocol for growing $E$. coli culture overnight in LB medium at $37^{\circ} \mathrm{C}$ (ref. 87) and purification was performed using a Qiagen Plasmid plus Maxi kit. Finally, DNA was eluted in 10 $\mathrm{mM}$ Tris- $\mathrm{HCl}$ buffer and stored at $-20{ }^{\circ} \mathrm{C}$. The concentration of plasmid DNA (512 $\mathrm{ng} \mu \mathrm{L}^{-1}$ ) was determined by measuring the absorbance of the DNA-containing solution at $260 \mathrm{~nm}$. One optical unit corresponds to $50 \mu \mathrm{g} \mathrm{mL}^{-1}$ of double stranded DNA.

The cleavage reaction of supercoiled pUC19 DNA by different concentrations of 1 was investigated by incubation of $512 \mathrm{ng}$ of plasmid in a $20 \mu \mathrm{L}$ reaction mixture in $40 \mathrm{mM}$ bicarbonate buffer ( $\mathrm{pH} 8.4$ ) at $37^{\circ} \mathrm{C}$, for $90 \mathrm{~min}$. The reaction mixtures were vortexed from time to time. The reaction was terminated by short centrifugation at an RCF of $6708 \times g$ and addition of $5 \mu \mathrm{L}$ of loading buffer [0.25\% bromophenol blue, $0.25 \%$ xylene cyanol $\mathrm{FF}$ and $30 \%$ glycerol in TAE buffer, pH 8.24 (40 mM Tris- 
acetate, $1 \mathrm{mM}$ EDTA)]. The samples were subjected to electrophoresis on 1\% agarose gel (Amersham Pharmacia-Biotech, Inc) prepared in TAE buffer $\mathrm{pH}$ 8.24. The electrophoresis was performed at a constant voltage $(80 \mathrm{~V})$ until bromophenol blue had passed through $75 \%$ of the gel. After electrophoresis, the gel was stained for $30 \mathrm{~min}$ by soaking it in an aqueous ethidium bromide solution $\left(0.5 \mu \mathrm{g} \mathrm{mL} \mathrm{m}^{-1}\right)$.

\section{HSA binding experiments}

Fatty acid free HSA $\left(<0.007 \%\right.$ fatty acids, $\left.M_{\mathrm{w}}=66478 \mathrm{Da}\right)$ was purchased from Sigma, as well as potassium dihydrogen phosphate, disodium hydrogen phosphate, sodium chloride and potassium chloride used for $1 \times$ PBS preparation. A stock solution of HSA $\left(c=2.78 \times 10^{-3} \mathrm{M}\right)$ was prepared by dissolving an accurately weighed mass of commercially available lyophilized HSA in freshly prepared $1 \times$ PBS $(\mathrm{pH}=7.35)$, and kept in a freezer in $100 \mu \mathrm{L}$ portions. A stock solution of $1(c=6.36 \times$ $10^{-4} \mathrm{M}$ ) was prepared by dissolving an appropriate amount of substance in DMSO. For HSA-1 interaction studies, the HSA solution was freshly prepared from the stock by dilution with PBS buffer (HSA concentration was kept constant, $c=5 \times 10^{-7}$ $\mathbf{M})$, and titrated with small volume increments of $\mathbf{1}$ stock solution (to avoid large sample dilution). The complex was added in $0.7,1.4,2.8,4.2,6.3,8.4$ and 10.5 molar equivalents. After each aliquot addition, the system was stirred and left to equilibrate for $15 \mathrm{~min}$ before UV-Vis absorption and fluorescence emission spectra recording. After the last equivalent, the total DMSO did not exceed $2 \%$ in volume. It was previously shown that addition of $15 \%$ of DMSO did not induce structural changes in bovine serum albumin, a protein structurally similar to HSA. ${ }^{\mathbf{8}}$ Therefore, it is unlikely that the conformation of HSA was changed with the level of DMSO used in this study. Millipore water was used for all aqueous solutions. All UV-Vis spectra were recorded against the corresponding blank (PBS) in the 250-450 $\mathrm{nm}$ wavelength range at room temperature.

Before recording the fluorescence spectrum, diluted HSA solution was ultrafiltrated using filters with $0.23 \mu \mathrm{m}$ pore size. The excitation wavelength was $280 \mathrm{~nm}$, with $5 \mathrm{~nm}$ slits; emission spectra were recorded in the 300-450 $\mathrm{nm}$ wavelength range, with $5 \mathrm{~nm}$ slits, and $0.1 \mathrm{~s}$ integration time. The background PBS signal was subtracted from each spectrum. In order to remove the instrumental inner filter effect, the absorbances were measured at the excitation $(280 \mathrm{~nm})$ and emission (340 $\mathrm{nm}$ ) wavelengths, and fluorescence intensities corrected according to the Lakowicz eqn (7): ${ }^{73}$

$$
F_{\text {corr }}=F_{\text {obs }} \times 10^{\frac{A_{\mathrm{ex}}+A_{\mathrm{em}}}{2}}
$$

where $F_{\text {corr }}$ and $F_{\text {obs }}$ are corrected and observed fluorescence intensities, and $A_{\text {ex }}$ and $A_{\text {em }}$ are absorbances at the excitation and emission wavelengths, respectively.

Fluorescence quenching data were processed using the Stern-Volmer eqn (8): ${ }^{73}$

$$
\frac{F_{0}}{F}=1+K_{\mathrm{sv}}[\mathrm{Q}]=1+K_{\mathrm{q}} \tau_{0}[\mathrm{Q}]
$$

where $F_{0}$ and $F$ represent HSA fluorescence intensities in the absence $\left(F_{0}\right)$ and in the presence of the quencher $(F), K_{\mathrm{sv}}$ and $K_{\mathrm{q}}$ are the Stern-Volmer quenching constant and the quenching rate constant of protein, respectively, $\tau_{0}$ is the average fluorescence lifetime (7.09 ns for HSA), ${ }^{74}$ and [Q] is the concentration of the quencher (1).

The quenching process was additionally analyzed using a modified Stern-Volmer eqn (9): ${ }^{73}$

$$
\frac{F_{0}}{\Delta F}=\frac{1}{f_{\mathrm{a}} K_{\mathrm{a}}} \frac{1}{[\mathrm{Q}]}+\frac{1}{f_{\mathrm{a}}}
$$

where $\Delta F$ is the difference in fluorescence intensity of HSA in the absence $\left(F_{0}\right)$ and in the presence of the quencher at concentration [Q]. $K_{\mathrm{a}}$ represents the effective quenching constant for the accessible fluorophores, and $f_{\mathrm{a}}$ is the fraction of accessible fluorophore.

Thermodynamic parameters of binding, the enthalpy $(\Delta H)$ and entropy change $(\Delta S)$, during the binding of 1 to HSA were determined by measuring the binding constants at several temperatures, and following the Van't Hoff eqn (10):

$$
\ln K_{\mathrm{a}}=-\frac{\Delta H}{R T}+\frac{\Delta S}{R}
$$

where $R$ is the universal gas constant, $T$ is the temperature (in $\mathrm{K}$ ), and $K_{\mathrm{a}}$ is the effective quenching constant at the corresponding temperature.

The distance between donor and acceptor, $r$, was calculated using eqn (11) for energy transfer efficiency, $E:^{73}$

$$
E=1-\frac{F}{F_{0}}=\frac{R_{0}{ }^{6}}{R_{0}{ }^{6}+r^{6}}
$$

where $R_{0}$ is called the Förster's distance, and represents the distance at which energy transfer is $50 \%$ efficient. $R_{0}$ is calculated according to eqn (12):

$$
R_{0}^{6}=8.79 \times 10^{-25} \kappa^{2} n^{-4} \phi J
$$

where $\kappa^{2}$ stands for the spatial orientation factor of the dipole, $n$ is a refractive index of the medium, $\phi$ is the donor fluorescence quantum yield, and $J$ is the overlap integral of the donor emission and the acceptor absorption spectra. The overlap integral, $J$, can be calculated according to eqn (13):

$$
J=\frac{\int_{0}^{\infty} F(\lambda) \varepsilon(\lambda) \lambda^{4} \mathrm{~d} \lambda}{\int_{0}^{\infty} F(\lambda) \mathrm{d} \lambda}
$$

where $F(\lambda)$ is fluorescence intensity (corrected for inner filter effect) of the donor in the wavelength of interest (in this case $300-450 \mathrm{~nm}$ ) and $\varepsilon$ is specific molar absorptivity of acceptor at certain wavelength. In the present study, $\kappa^{2}=2 / 3$ (for randomly oriented dipoles), $n=1.336$, and $\phi=0.118$ were used. ${ }^{89}$

\section{Computational details}

Theoretical IR spectrum of 1 . The geometry of 1 was optimized and vibrational frequencies were calculated at the $\mathrm{B}^{97 \mathrm{D}^{90}}$ /TZVP ${ }^{91,92}$ level of theory in Gaussian 09, Revision D.01 software. ${ }^{93}$ The IR spectrum was visualized using GaussView $5,{ }^{94}$ 
and the corresponding data were exported as a text file in the range $0-4000 \mathrm{~cm}^{-1}$ with step size $1 \mathrm{~cm}^{-1}$.

Molecular docking studies. Two randomly chosen X-ray crystal structures of dodecamer d(CGCGAATTCGCG) $)_{2}$, PDB ID: $3 \mathrm{U} 2 \mathrm{~N}^{95}$ and PDB ID: $4 \mathrm{U} 8 \mathrm{~A},{ }^{96}$ and three HSA structures, PDB IDs: $1 \mathrm{BJ} 5,{ }^{97} 2 \mathrm{BXD}^{98}$ and $4 \mathrm{~L} 9 \mathrm{Q},{ }^{99}$ were obtained from the Protein Data Bank (http://www.rcsb.org/pdb). The active sites were identified according to positions of crystallized ligands in the PDB structures. Ligands were removed, as well as water and ions and structures were prepared for docking using Autodock Tools 1.5.6. ${ }^{100,101}$ Docking was carried in Autodock Vina 1.1.2. ${ }^{102}$ The grid box size was set to $24 \times 24 \times 24 \AA$ and exhaustiveness to 250. All calculations were carried on PARADOX computer cluster (Scientific Computing Laboratory of the Institute of Physics, Belgrade, Serbia). Hqasesc and 1 were prepared using $\mathrm{X}$-ray determined coordinates, with Gasteiger charge correction done with Chimera program, ${ }^{\mathbf{1 0 3}}$ as no charges were assigned for selenium atoms.

\section{Acknowledgements}

The authors acknowledge networking support by the COST Action CM1106 StemChem - "Chemical Approaches to Targeting Drug Resistance in Cancer Stem Cells". The work was founded by the Ministry of Education, Science and Technological Development of the Republic of Serbia (Grants 172055 and 172013). PARADOX computer cluster is supported in part by the Ministry of Education, Science and Technological Development of the Republic of Serbia (No. 171017) and by the European Commission under the FP7 projects (HP-SEE, PRACE-1IP, PRACE-2IP, EGI-InSPIRE).

\section{References}

1 T. S. Lobana, R. Sharma, G. Bawa and S. Khanna, Coord. Chem. Rev., 2009, 253, 977-1055.

2 J. S. Casas, M. S. Garcia-Tasende and J. Sordo, Coord. Chem. Rev., 2000, 209, 197-261.

3 H. Beraldo and D. Gambino, Mini-Rev. Med. Chem., 2004, 4, 159-165.

4 D. S. Kalinowski, P. Quach and D. R. Richardson, Future Med. Chem., 2009, 1, 1143-1151.

5 N. S. H. N. Moorthy, N. M. F. S. A. Cerqueira, M. J. Ramos and P. A. Fernandes, Recent Pat. Anti-Cancer Drug Discovery, 2013, 8, 168-182.

6 G. Pelosi, Open Crystallogr. J., 2010, 3, 16-28.

7 N. S. H. N. Moorthy, N. M. F. S. A. Cerqueira, M. J. Ramos and P. A. Fernandes, Mini-Rev. Med. Chem., 2013, 13, 1862-1872.

8 B. Shakya, P. N. Yadav, J. Ueda and S. Awale, Bioorg. Med. Chem. Lett., 2014, 24, 458-461.

9 T. A. Yousef, G. M. Abu El-Reash, O. A. El-Gammal and S. F. Ahmed, Polyhedron, 2014, 81, 749-763.

10 A. Y. Lukmantara, D. S. Kalinowski, N. Kumar and D. R. Richardson, J. Inorg. Biochem., 2014, 141, 43-54.

11 C. Gan, J. Cui, S. Su, Q. Lin, L. Jia, L. Fan and Y. Huang, Steroids, 2014, 87, 99-107.
12 A. Mrozek-Wilczkiewicz, M. Serda, R. Musiol, G. Malecki, A. Szurko, A. Muchowicz, J. Golab, A. Ratuszna and J. Polanski, ACS Med. Chem. Lett., 2014, 5, 336-339.

13 M. A. Bhat, A. Al-Dhfyan, A. A. Khan, N. Al-Harbi, P. S. Manogaran, A. M. Alanazi, H. K. Fun and M. A. AlOmar, Bioorg. Med. Chem. Lett., 2015, 25, 83-87.

14 N. Filipović, N. Polović, B. Rašković, S. Misirlić-Denčić, M. Dulović, M. Savić, M. Nikšić, D. Mitić, K. Anđelković and T. Todorović, Monatsh. Chem., 2014, 145, 1089-1099.

15 A. Molter, J. Rust, C. W. Lehmann, G. Deepa, P. Chiba and F. Mohr, Dalton Trans., 2011, 40, 9810-9820.

16 A. Molter, G. N. Kaluđerović, H. Kommera, R. Paschke, T. Langer, R. Pöttgen and F. Mohr, J. Organomet. Chem., 2012, 70, 80-86.

17 V. Zaharia, A. Ignat, B. Ngameni, V. Kuete, M. L. Moungang, C. N. Fokunang, M. Vasilescu, N. Palibroda, C. Cristea, L. Silaghi-Dumitrescu and B. T. Ngadjui, Med. Chem. Res., 2013, 22, 5670-5679.

18 H. Shen, H. Zhu, M. Song, Y. Tian, Y. Huang, H. Zheng, R. Cao, J. Lin, Z. Bi and W. Zhong, BMC Cancer, 2014, 14, 629-639.

19 M. D. Revenko, V. I. Prisacari, A. V. Dizdari, E. F. Stratulat, I. D. Corja and L. M. Proca, Pharm. Chem. J., 2011, 45, 351354.

20 K. C. Agrawal, B. A. Booth, R. L. Michaud, E. C. Moore and A. C. Sartorelli, Biochem. Pharmacol., 1974, 23, 2421-2429.

21 C. R. Kowol, R. Eichinger, M. A. Jakupec, M. Galanski, V. B. Arion and B. K. Keppler, J. Inorg. Biochem., 2007, 100, 1946-1957.

22 C. Pizzo, P. Faral-Tello, G. Salinas, M. Flo, C. Robello, P. Wipfe and S. G. Mahler, Med. Chem. Commun., 2012, 3, 362-368.

23 S. R. Turk, C. Shipman Jr and J. C. Drach, J. Gen. Virol., 1986, 67, 1625-1632.

24 V. Calcatierra, O. Lopez, J. G. Fernandez-Bolanos, G. B. Plata and J. M. Padron, Eur. J. Med. Chem., 2015, 94, 63-72.

25 T. R. Todorović, A. Bacchi, G. Pelizzi, N. O. Juranić, D. M. Sladić, I. D. Brčeski and K. K. Anđelković, Inorg. Chem. Commun., 2006, 9, 862-865.

26 T. R. Todorović, A. Bacchi, N. O. Juranić, D. M. Sladić, G. Pelizzi, T. T. Božić, N. R. Filipović and K. K. Anđelković, Polyhedron, 2007, 26, 3428-3436.

27 S. Bjelogrlić, T. Todorović, A. Bacchi, M. Zec, D. Sladić, T. Srdić-Rajić, D. Radanović, S. Radulović, G. Pelizzi and K. Anđelković, J. Inorg. Biochem., 2010, 104, 673-682.

28 N. Gligorijević, T. Todorović, S. Radulović, D. Sladić, N. Filipović, D. Gođevac, D. Jeremić and K. Anđelković, Eur. J. Med. Chem., 2009, 44, 1623-1629.

29 T. Srdić-Rajić, M. Zec, T. Todorović, K. Anđelković and S. Radulović, Eur. J. Med. Chem., 2011, 46, 3734-3747.

30 M. Zec, T. Srdić-Rajić, A. Krivokuća, R. Janković, T. Todorović, K. Andjelković and S. Radulović, Med. Chem., 2014, 10, 759-771.

31 M. Zec, T. Srdić-Rajić, A. Konić-Ristić, T. Todorović, K. Andjelković, I. Filipović-Ljesković and S. Radulović, Anti. Canc. Agents Med. Chem., 2014, 10, 1071-1080. 
32 P. A. Sotiropoulou, M. S. Christodoulou, A. Silvani, C. Herold-Mende and D. Passarella, Drug Discovery Today, 2014, 19, 1547-1562.

33 J. P. Thiery, H. Acloque, R. Y. Huang and M. A. Nieto, Cell, 2009, 139, 871-890.

34 B. Beck and C. Blanpain, Nat. Rev. Cancer, 2013, 13, 727738.

35 F. H. Sarkar, Y. Li, Z. Wang and D. Kong, Minerva Chir., 2009, 64, 489-500.

36 T. Arumugam, V. Ramachandran, K. F. Fournier, H. Wang, L. Marquis and J. L. Abbruzzese, Cancer Res., 2009, 69, 5820-5828.

37 D. Kovala-Demertzi, P. N. Yadav, J. Wiecek, S. Skoulika, T. Varadinova and M. A. Demertzis, J. Inorg. Biochem., 2006, 100, 1558-1567.

38 D. Kovala-Demertzi, A. Alexandratos, A. Papageorgiou, P. N. Yadav, P. Dalezis and M. A. Demertzis, Polyhedron, 2008, 27, 2731-2738.

39 C. R. Kowol, E. Reisner, I. Chiorescu, V. B. Arion, M. Galanski, D. V. Deubel and B. K. Keppler, Inorg. Chem., 2008, 47, 11032-11047.

40 E. Lopez-Torres, M. A. Mendiola, J. Rodrıguez-Procopio, M. T. Sevilla, E. Colacio, J. M. Moreno and I. Sobrados, Inorg. Chim. Acta, 2001, 323, 130-138.

41 J. Wang, Analytical Electrochemistry, Wiley-VCH, New York, 2nd edn, 2000, p. 34.

42 P. S. Zhao, H. Y. Wang, J. Song and L. D. Lu, Struct. Chem., 2010, 21, 977-987.

43 A. Albert and E. P. Serjeant, The determination of Ionization constants, Chapman and Hall, London, 2nd edn, 1971, p. 44.

44 C. F. Macrae, I. J. Bruno, J. A. Chisholm, P. R. Edgington, P. McCabe, E. Pidcock, L. Rodriguez-Monge, R. Taylor, J. van de Streek and P. A. Wood, J. Appl. Crystallogr., 2008, 41, 466-470.

45 F. H. Allen, Acta Crystallogr., Sect. B: Struct. Sci., 2002, 58, 380-388.

46 T. R. Todorović, A. Bacchi, D. M. Sladić, N. M. Todorović, T. T. Božić, D. D. Radanović, N. R. Filipović, G. Pelizzi and K. K. Anđelković, Inorg. Chim. Acta, 2009, 362, 3813-3820.

47 E. Manoj and M. R. P. Kurup, Polyhedron, 2008, 27, 275-282. 48 X. Fan, J. Dong, R. Min, Y. Chen, X. Yi, J. Zhou and S. Zhang, J. Coord. Chem., 2013, 66, 4268-4279.

49 S. Zhang, J. Dong, X. Fan, Y. Chen and J. Zhou, J. Coord. Chem., 2012, 65, 3098-3110.

50 D. X. West, P. M. Ahrweiler, G. Ertem, J. P. Scovill, D. L. Klayman, J. L. Flippen-Anderson, R. Gilardi, C. George and L. K. Pannell, Transition Met. Chem., 1985, 10, 264-270.

51 M. T. Zimmerman, C. A. Bayse, R. R. Ramoutar and J. L. Brumaghim, J. Inorg. Biochem., 2015, 145, 30-40.

52 R. L. Prior, X. Wu and K. Schaich, J. Agric. Food Chem., 2005, 53, 4290-4302.

53 L. Galluzzi, I. Vitale, J. M. Abrams, E. S. Alnemri, E. H. Baehrecke, M. V. Blagosklonny, T. M. Dawson, V. L. Dawson, W. S. El-Deiry, S. Fulda, E. Gottlieb, D. R. Green, M. O. Hengartner, O. Kepp, R. A. Knight,
S. Kumar, S. A. Lipton, X. Lu, F. Madeo, W. Malorni, P. Mehlen, G. Nuñez, M. E. Peter, M. Piacentini, D. C. Rubinsztein, Y. Shi, H. U. Simon, P. Vandenabeele, E. White, J. Yuan, B. Zhivotovsky, G. Melino and G. Kroemer, Cell Death Differ., 2012, 19, 107-120.

54 S. H. Lee, X. W. Meng, K. S. Flatten, D. A. Loegering and S. H. Kaufmann, Cell Death Differ., 2013, 20, 64-76.

55 D. V. Krysko, T. Vanden Berghe, K. D'Herde and P. Vandenabeele, Methods, 2008, 44, 205-221.

56 G. Kroemer and S. J. Martin, Nat. Med., 2005, 11, 725-730.

57 D. R. McIlwain, T. Berger and T. W. Mak, Cold Spring Harbor Perspect. Biol., 2013, 5, a008656.

58 J. Puccini, L. Dorstyn and S. Kumar, Cell Death Differ., 2013, 20, 1133-1139.

59 A. Oleksi, A. G. Blanco, R. Boer, J. Usón, J. Aymamí, A. Rodger, M. J. Hannon and M. Coll, Angew. Chem., Int. Ed., 2006, 45, 1227-1231.

60 A. Terenzi, G. Barone, A. Silvestri, A. M. Giuliani, A. Ruggirello and V. T. Liveri, J. Inorg. Chem., 2009, 103, 1-9.

61 R. Eshkourfu, B. Čobeljić, M. Vujčić, I. Turel, A. Pevec, K. Sepčić, M. Zec, S. Radulović, T. Srdić-Radić, D. Mitić, K. Andjelković and D. Sladić, J. Inorg. Biochem., 2011, 105, 1196-1203.

62 C. Y. Gao, X. Qiao, Z. Y. Ma, Z. G. Wang, J. Lu, J. L. Tian, J. Y. Xu and S. P. Yan, Dalton Trans., 2012, 41, 12220-12232.

63 Z. Jannesari, H. Hadadzadeh, Z. Amirghofran, J. Simpson, T. Khayamian and B. Maleki, Spectrochim. Acta, Part A, 2015, 136, 1119-1133.

64 C. Icsel and V. T. Yilmaz, J. Photochem. Photobiol., B, 2014, 130, 115-121.

65 M. Cory, D. D. Mckee, J. Kagan, D. W. Henry and J. A. Miller, J. Am. Chem. Soc., 1985, 107, 2528-2536.

66 J. Wang, L. Shuai, X. Xiao, Y. Zeng, Z. Li and T. MatsumuraInoue, J. Inorg. Biochem., 2005, 99, 883-885.

67 N. C. Garbett, N. B. Hammond and D. E. Graves, Biophys. J., 2004, 87, 3974-3981.

68 Y. Shi, C. Guo, Y. Sun, Z. Liu, F. Xu, Y. Zhang, Z. Wen and Z. Li, Biomacromolecules, 2011, 12, 797-803.

69 F. G. Loontiens, P. Regenfuss, A. Zechel, L. Dumortier and R. M. Clegg, Biochemistry, 1990, 29, 9029-9039.

70 A. Adhikary, V. Buschmann, C. Müller and M. Sauer, Nucleic Acids Res., 2003, 31, 2178-2186.

71 J. Chen and J. Stubbe, Curr. Opin. Chem. Biol., 2004, 8, 175181.

72 B. Birdsall, R. W. King, M. R. Wheeler, C. A. Lewis, S. R. Goode, R. B. Dunlap and G. C. K. Roberts, Anal. Biochem., 1983, 132, 353-361.

73 J. R. Lakowicz, Principles of Fluorescence Spectroscopy, Springer Science Business Media, New York, USA, 3rd edn, 2006, pp. 11, 56 and 289.

74 M. Amiri, K. Jankeje and J. R. Albani, J. Fluoresc., 2010, 20, 651-656.

75 M. R. Eftink and C. A. Ghiron, Anal. Biochem., 1981, 114, 199-227.

76 P. D. Ross and S. Subramanian, Biochemistry, 1981, 20, 3096-3102. 
77 Y. Hu, Y. Liu, J. Wang, X. Xiao and S. Qu, J. Pharm. Biomed. Anal., 2004, 36, 915-919.

78 G. Sudlow, D. J. Birkett and D. N. Wade, Mol. Pharmacol., 1975, 11, 824-832.

79 CrysAlisPro Software system, Agilent Technologies UK Ltd., Oxford, 2014.

80 G. M. Sheldrick, Acta Crystallogr., Sect. A: Found. Adv., 2015, 71, 3-8.

81 G. M. Sheldrick, Acta Crystallogr., Sect. C: Struct. Chem., 2015, 71, 3-8.

82 C. B. Hübschle, G. M. Sheldrick and B. Dittrich, J. Appl. Crystallogr., 2011, 44, 1281-1284.

83 A. L. Spek, Acta Crystallogr., Sect. D: Biol. Crystallogr., 2009, 65, 148-155.

84 S. Léonce, V. Pérez, S. Lambel, D. Peyroulan, F. Tillequin, S. Michel, M. Koch, B. Pfeiffer, G. Atassi, J. A. Hickman and A. Pierré, Mol. Pharmacol., 2001, 60, 1383-1391.

85 M. E. Reichmann, S. A. Rice, C. A. Thomas and P. Doty, J. Am. Chem. Soc., 1954, 76, 3047-3053.

86 R. Vijayalakshmi, M. Kanthimathi, V. Subramanian and B. Unni Nair, Biochem. Biophys. Res. Commun., 2000, 271, 731-734.

87 J. Sambrook, E. F. Fritsch and T. Maniatis, Molecular Cloning: A Laboratory Manual, Cold Spring Harbor Laboratory Press, USA, 2nd edn, 1989, pp. 133-134.

88 B. Ojha and G. Das, J. Phys. Chem. B, 2010, 114, 3979-3986.

89 F. L. Cui, J. Fan, J. P. Li and Z. D. Hu, Bioorg. Med. Chem., 2004, 12, 151-157.

90 S. Grimme, J. Comput. Chem., 2006, 27, 1787-1799.

91 A. Schaefer, H. Horn and R. Ahlrichs, J. Chem. Phys., 1992, 97, 2571-2577.

92 A. Schaefer, C. Huber and R. Ahlrichs, J. Chem. Phys., 1994, 100, 5829-5835.

93 M. J. Frisch, G. W. Trucks, H. B. Schlegel, G. E. Scuseria, M. A. Robb, J. R. Cheeseman, G. Scalmani, V. Barone, B. Mennucci, G. A. Petersson, H. Nakatsuji, M. Caricato, X. Li, H. P. Hratchian, A. F. Izmaylov, J. Bloino, G. Zheng, J. L. Sonnenberg, M. Hada, M. Ehara, K. Toyota, R. Fukuda, J. Hasegawa, M. Ishida, T. Nakajima,
Y. Honda, O. Kitao, H. Nakai, T. Vreven, J. A. Montgomery Jr, J. E. Peralta, F. Ogliaro, M. Bearpark, J. J. Heyd, E. Brothers, K. N. Kudin, V. N. Staroverov, T. Keith, R. Kobayashi, J. Normand, K. Raghavachari, A. Rendell, J. C. Burant, S. S. Iyengar, J. Tomasi, M. Cossi, N. Rega, J. M. Millam, M. Klene, J. E. Knox, J. B. Cross, V. Bakken, C. Adamo, J. Jaramillo, R. Gomperts, R. E. Stratmann, O. Yazyev, A. J. Austin, R. Cammi, C. Pomelli, J. W. Ochterski, R. L. Martin, K. Morokuma, V. G. Zakrzewski, G. A. Voth, P. Salvador, J. J. Dannenberg, S. Dapprich, A. D. Daniels, O. Farkas, J. B. Foresman, J. V. Ortiz, J. Cioslowski and D. J. Fox, Gaussian 09 (Revision D.01), Gaussian Inc., Wallingford CT, 2013.

94 R. Dennington, T. Keith and J. Millam, GaussView, version 5, Semichem Inc., Shawnee Mission, KS, 2009.

95 D. G. Wei, W. D. Wilson and S. Neidle, J. Am. Chem. Soc., 2013, 135, 1369-1377.

96 W. Zhu, Y. Wang, K. Li, J. Gao, C. H. Huang, C. C. Chen, T. P. Ko, Y. Zhang, R. T. Guo and E. Oldfield, J. Med. Chem., 2015, 58, 1215-1227.

97 S. Curry, H. Mandelkow, P. Brick and N. Franks, Nat. Struct. Biol., 1998, 5, 827-835.

98 J. Ghuman, P. A. Zunszain, I. Petitpas, A. A. Bhattacharya, M. Otagiri and S. Curry, J. Mol. Biol., 2005, 353, 38-52.

99 Z. M. Wang, J. X. Ho, J. R. Ruble, J. Rose, F. Ruker, M. Ellenburg, R. Murphy, J. Click, E. Soistman, L. Wilkerson and D. C. Carter, Biochim. Biophys. Acta, 2013, 1830, 5356-5374.

100 M. F. Sanner, J. Mol. Graphics Modell., 1999, 17, 57-61.

101 G. M. Morris, R. Huey, W. Lindstrom, M. F. Sanner, R. K. Belew, D. S. Goodsell and A. J. Olson, J. Comput. Chem., 2009, 16, 2785-2791.

102 O. Trott and A. J. Olson, J. Comput. Chem., 2010, 31, 455461.

103 E. F. Pettersen, T. D. Goddard, C. C. Huang, G. S. Couch, D. M. Greenblatt, E. C. Meng and T. E. Ferrin, J. Comput. Chem., 2004, 25, 1605-1612. 